\title{
La necrópolis de Can Gambús-1 (Sabadell, Barcelona). Nuevos conocimientos sobre las prácticas funerarias durante el Neolítico medio en el Noreste de la Península Ibérica
}

\author{
The necropolis of Can Gambus-1 (Sabadell, Barcelona). New data on the funerary \\ practices during the Middle Neolithic in the northeast of the Iberian Peninsula
}

\author{
Jordi Roig (*) \\ Joan Manel Coll (*) \\ Juan Francisco Gibaja (**) \\ Philippe Chambon (***)
}

\author{
Vàngelis Villar $(* * * *)$ \\ Jordi Ruiz (****) \\ Xavier Terradas $(* * * * *)$ \\ Maria Eulàlia Subirà $(* * * *)$
}

\section{RESUMEN}

Presentamos el conjunto de inhumaciones de Can Gambús-1, de cronología neolítica y asociadas a la denominada "Cultura de los Sepulcros de Fosa" (finales del V a inicios del IV milenio cal BC). El objetivo principal es informar de las novedades relativas a los procedimientos de construcción de las fosas y a los materiales empleados en la cobertura de las sepulturas, además del tratamiento dado a algunos de los cadáveres. Ello ha sido posible gracias al excepcional estado de conservación de dichas sepulturas, a su riguroso proceso de excavación arqueológica y a su estudio antropológico y taxonómico detallado a partir de todas las evidencias disponibles. Asimismo, se presentan los ajuares recuperados en las inhumaciones cuya riqueza es notable en comparación con la de otros contextos funerarios similares. Probablemente este dato esté relacionado con la presencia exclusiva de individuos adultos entre los inhumados.

\footnotetext{
ABSTRACT

In this paper we deal with the Neolithic burials at the site of Can Gambús-1, belonging of the so called

(*) Arrago sl. Sant Cugat 76 Baixos - 08201 Sabadell (Barcelona). Correos electrónicos: jordiroig@arragosl.com; info@arragosl.com

(**) Becario postdoctoral de FCT adscrito a la Universidade do Algarve. Faculdade de Ciências Humanas e Sociais. Campus de Gambelas, 8000-117 Faro (Portugal). Correo electrónico: jfgibaja@ualg.pt

(***) CNRS-UMR 7041, Ethnologie préhistorique. Maison de l'Archéologie et de l'Ethnologie. 21 allée de 1'Université. F-92023 Nanterre cedex (Francia). Correo electrónico: philippe.chambon@mae.u-paris10.fr
}

\begin{abstract}
"Cultura de los Sepulcros de Fosa" (from end of the fifth to the beginning of the fourth millennia cal $B C$ ). The main aim is to present new data on the procedures of excavation of the pits, the materials used in the covering of the graves and the treatment given to some of the corpses. The detailed archaeological reconstruction of the funerary behaviour has been possible thanks to the exceptional state of preservation of the graves, the rigorous process of archaeological excavation, the anthropological study carried out, as well as to the achievement of a detailed taxonomic study of all the available evidences. Likewise, the grave goods recovered in the burials are presented. Their quantity and quality is outstanding compared with other similar funerary contexts. Probably this fact is due to the exclusive presence of adult individuals among the buried ones.
\end{abstract}

Palabras clave: Mediterráneo occidental; Neolítico; Arqueología de la muerte; Ritual funerario; Paleoantropología; Tafonomía; Carbono 14; Ajuares; Tecnología.

Key words: Western Mediterranean; Neolithic; Archaeology of Death; Funerary Ritual; Paleoanthropology; Taphonomy; Radiocarbon; Grave Goods; Technology.

(****) GRAPAC (Grup de Recerca Aplicada al Patrimoni Cultural), Unitat d'Antropologia Biològica, Departament de Biologia Animal, de Biologia Vegetal i d'Ecologia, Facultat de Biociències, Universitat Autònoma de Barcelona, 08193 Bellaterra (España). Correos electrónicos:

vangelis.villar@gmail.com; jordidroj@hotmail.com;

Eulalia.Subira@uab.cat

(*****) CSIC-IMF. Departmento de Arqueología y Antropología. Egipcíaques 15. 08001 Barcelona. Correo electrónico: terradas@imf.csic.es

Recibido: 31-VIII-2009; aceptado: 2-XI-2009. 


\section{LA NECRÓPOLIS DEL CAN GAMBÚS-1 EN EL CONTEXTO DEL V-IV MILENIO CAL BC}

A finales del $\mathrm{V}$ milenio e inicios del IV milenio cal $\mathrm{BC}$, las comunidades neolíticas del noreste de la Península Ibérica parecen asentarse preferentemente en los valles y las áreas de llanura próximas a la costa mediterránea, zonas en las que las condiciones ecológicas y paisajísticas permitían, sin duda, la implantación de la agricultura y la ganadería. Pero si hay algo que por antonomasia ha caracterizado a este período y a los grupos neolíticos de este momento son sus prácticas funerarias. Tanto es así que el término "Cultura de los Sepulcros de Fosa", acuñado por P. Bosch Gimpera en su obra Prehistoria catalana (1919), sigue manteniendo su vigencia.

Hoy, gracias al desarrollo de la investigación, a los nuevos métodos de excavación, al cuidado del registro arqueológico, a la aplicación de más y novedosos análisis y a la cada vez más frecuente datación de los yacimientos, conocemos mucho mejor algunos aspectos concernientes a la organización económica, social e incluso simbólica de estas comunidades. Sabemos qué variedades de cereales cultivaban, qué especies de animales domésticos y salvajes explotaban, cómo eran sus instrumentos, de dónde procedían, para qué se usaron o qué papel tuvieron determinados ornamentos y materiales en la esfera simbólica por aparecer habitualmente en contextos funerarios.

Sin embargo, prácticamente no sabemos nada acerca de sus viviendas, ni de cómo se estructuraba el espacio y las actividades en su interior. Supuestamente sus hábitats han quedado arrasados y destruidos por los continuos procesos erosivos naturales y antrópicos que se han producido durante todos estos siglos. Contrariamente, aquellas estructuras realizadas en el subsuelo, a una cierta profundidad, han llegado hasta nosotros más o menos en buen estado, de ahí que el registro arqueológico mejor conocido y referenciado del Neolítico medio del noreste peninsular provenga de las sepulturas, las fosas de almacenamiento o desecho y de las minas de Gavà.

En lo referente a las prácticas funerarias, que es el tema que nos ocupa, durante el $\mathrm{V}$ milenio se documentan diversos enterramientos, habitualmente múltiples, en cuevas y abrigos y los prime- ros enterramientos, individualizados o formando necrópolis, en fosas, cistas o pequeños dólmenes (Gibaja 2004). Los casos más conocidos, algunos excavados afortunadamente en los últimos decenios, son los sepulcros de fosa de la necrópolis de Sant Pau del Camp (Barcelona; Molist et al. 2008), el grupo de sepulturas megalíticas de Tavertet (Osona, Barcelona; Molist et al. 1987), las sepulturas en fosa y cista de la desembocadura del Ebro (Tarragona; Esteve 1999), los enterramientos en fosa de Hort d'en Grimau (Castellví de la Marca, Barcelona; Mestres 1988) o algunas de las últimas sepulturas descubiertas en ciertas bocaminas de Gavà (Gavà, Barcelona; Borrell et al. 2005).

A partir del IV milenio estas prácticas funerarias se generalizan (Martín 2009). Los casos más representativos son las más de 130 tumbas halladas en la Bòbila Madurell (Sant Quirze del Vallès, Barcelona; Gibaja 2003), las 25 descubiertas en el Camí de Can Grau [La Roca del Vallès, Barcelona; Martí et al. 1997, Pou y Martí 1995 (1)], las 16 del Puig d'en Roca (Girona; Riuró y Fusté 1980), las 8 del Pla del Riu de les Marcetes (Manresa, Barcelona; Guitart 1986) o las 7 del Llord (Castellar de la Ribera, Lleida; Muñoz 1965).

Estos enterramientos en fosa o en cista corresponden mayoritariamente a inhumaciones individuales, acompañadas de un ajuar compuesto por vasos cerámicos, núcleos, láminas, puntas o geométricos de sílex, molinos, hachas y azuelas pulimentadas, punzones y espátulas de hueso, colmillos perforados de jabalí, cuentas de piedra con las que se han confeccionado collares y pulseras, etc.

En este contexto, Can Gambús-1 es la última de las grandes necrópolis excavadas en Cataluña perteneciente a inicios del IV milenio cal BC. El objetivo principal de este trabajo es dar a conocer este conjunto funerario y las novedades que está aportando, en especial todas aquellas relativas a los procesos de excavación de las fosas y a los materiales empleados en la cobertura de las sepulturas, además del tratamiento dado a algunos de los cadáveres y de los ajuares vinculados a los mismos.

(1) Pou, R. y Martí, M. 1995: Els sepulcres de Fosa al Vallès. Estudi de les necròpolis de la Bòbila Madurell i el Cami de Can Grau. Trabajo de investigación del Tercer ciclo universitario. Universitat Autònoma de Barcelona. 


\section{CAN GAMBÚS-1: SITUACIÓN GEOGRÁFICA E INTERVENCIONES ARQUEOLÓGICAS}

La necrópolis neolítica de Can Gambús-1 se localiza en el término municipal de Sabadell (Barcelona), próximo al límite administrativo de la vecina población de Sant Quirze del Vallès, en el Vallès Occidental (Fig. 1). Esta comarca se sitúa en la llamada fosa tectónica del Vallès-Penedès, encajada entre las sierras litorales y prelitorales catalanas, y constituye un corredor natural paralelo a la costa, con una orientación NE-SO. Gran parte de esta fosa está compuesta por arcillas cuaternarias procedentes de las sierras circundantes que cubren de manera desigual una secuencia de conglomerados, costras carbonatadas $\mathrm{y}$ arcillas del Mioceno superior. Debió ser una zona excelente para las actividades agropecuarias practicadas por las comunidades neolíticas, ya que es un paraje regado por numerosas fuentes de agua, compuesto por sedimentos arcillosos y caracterizado por un clima mediterráneo.

Se trata de una zona conocida ampliamente por su riqueza arqueológica, ya que durante más de un siglo se han llevado a cabo múltiples excavaciones en el cercano yacimiento de la Bòbila Madurell-Can Feu. Las intervenciones arqueológicas en Can Gambús se sitúan en el tramo central de la Sierra de Can Feu, que desciende en una suave pendiente desde los $226 \mathrm{~m}$ de altitud en su parte más alta, hasta los $195 \mathrm{~m}$ en su cota inferior. En total estamos hablando de un área excavada de 75 ha a cargo de dos empresas de arqueología distintas: Can Gambús-1 en la mitad sur y Can

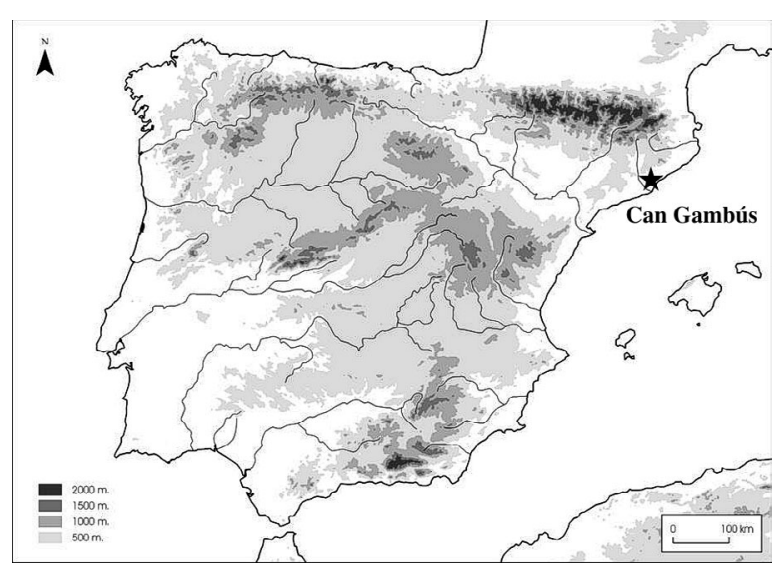

Fig. 1. Localización geográfica del yacimiento de Can Gambús-1 (Sabadell, Barcelona).
Gambús-2 en la mitad norte. En Can Gambús-1 las primeras excavaciones se llevaron a cabo durante los años 2003-2006 sobre una superficie aproximada de unas 30 ha por el equipo de arqueólogos de la empresa ARRAGO S.L. Arqueologia i Patrimoni, bajo la dirección de Jordi Roig Buxó y Joan-Manuel Coll Riera, con la coordinación del Museu d'Història de Sabadell (2). Durante estos años fueron excavadas 625 estructuras arqueológicas negativas localizadas en los niveles de arcillas con carbonataciones y en los niveles de limos y gravas. Su profundidad oscila entre los 20 y $270 \mathrm{~cm}$, dependiendo del tipo de estructura, el sector donde se excavó y su grado de preservación: hay zonas que han sufrido mucho más los efectos de la erosión natural y de las actividades agrícolas practicadas durante décadas.

Las estructuras configuran un importante complejo arqueológico, con un abanico cronológico muy amplio. Definen diversos yacimientos con su propia homogeneidad y especificidad. Se han registrado estructuras y materiales pertenecientes al Neolítico antiguo Cardial, Neolítico medio, Neolítico final, Bronce inicial, Bronce final, Primera Edad del Hierro, Época Ibérica, Época Romana, Antigüedad Tardía, Época Altomedieval, Época Bajomedieval, Época Moderna y Época Contemporánea [Roig y Coll 2007, 2008 (3), e.p.]. Precisamente, por su interés histórico y su riqueza arqueológica sobresalen especialmente la necrópolis del Neolítico medio y el poblado de la Antigüedad Tardía en el que se han documentado hasta 232 estructuras, de las cuales 35 también son funerarias (4).

\section{LAS ESTRUCTURAS FUNERARIAS NEOLÍTICAS DE CAN GAMBÚS-1}

En la necrópolis neolítica de Can Gambús-1 hemos documentado 47 estructuras funerarias, de las cuales 43 son enterramientos individuales y 4 dobles (Fig. 2 y Lám. I). En estas cuatro las inhu-

(2) Algunas de las analíticas se financiaron gracias a la ayuda económica de la Junta de Compensación, la propia empresa Arrago S.L., y en menor medida, el Museu d'Història de Sabadell y el Servei d'Arqueologia de la Generalitat de Catalunya.

(3) Roig, J. y Coll, J.M.: Memòria de la intervenció arqueolòica a Can Gambús 1 (Sabadell, Vallès Occ.), abril 2003 - desembre 2004 i agost 2006, Memória inédita depositada en el Servei d'Arqueologia de la Generalitat de Catalunya. Barcelona, julio 2008.

(4) Véase nota 3. 


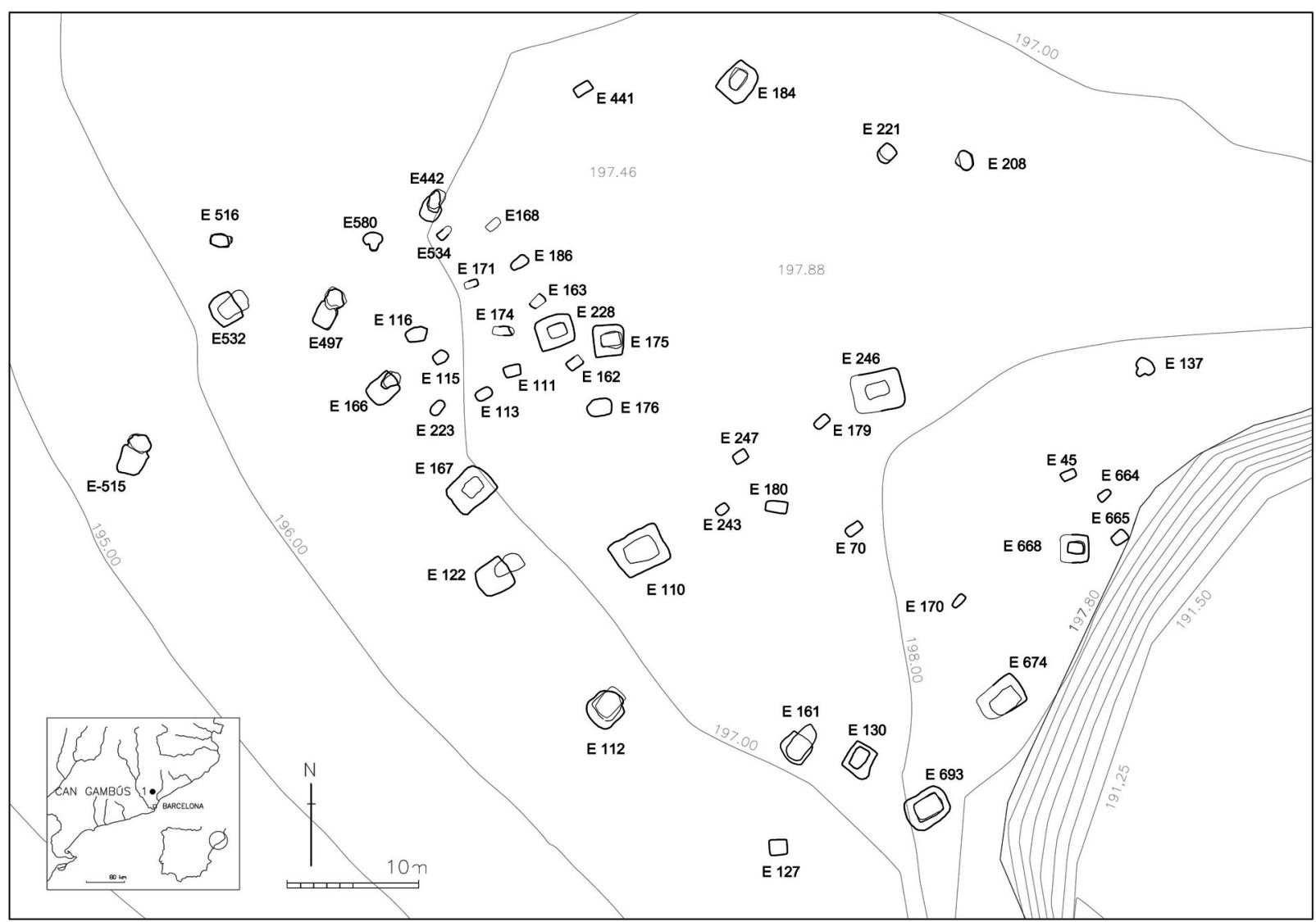

Fig. 2. Planta general de la necrópolis del Neolítico medio de Can Gambús-1 (Sabadell, Barcelona) (J. Roig y J.M. Coll).

maciones se han efectuado simultáneamente en el sepulcro E515 y de manera sucesiva en los sepulcros E247, E497 y E580, como demuestra el arrinconamiento del primer inhumado en ciertas zonas

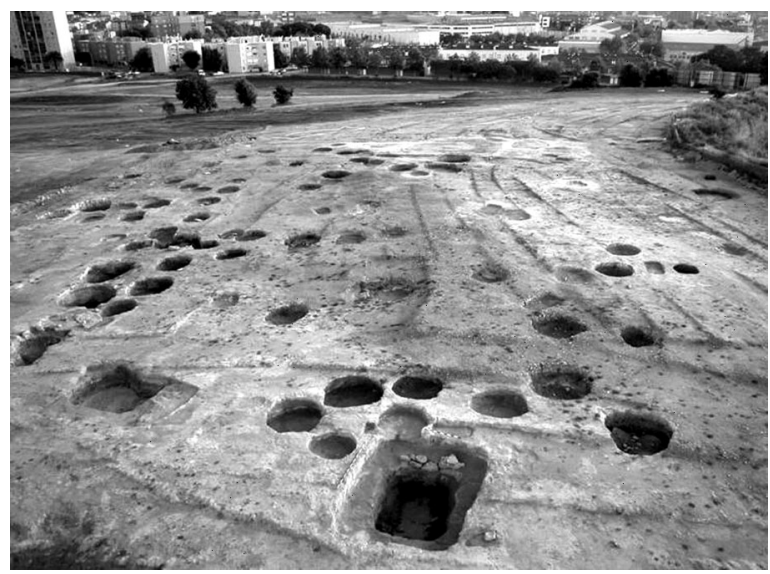

Lám. I. Foto general de la necrópolis del Neolítico medio de Can Gambús-1 (Sabadell, Barcelona) (J. Roig y J.M. Coll). del enterramiento [Roig y Coll 2007, 2008 (5), e.p.]. Del total de 51 individuos masculinos y femeninos, 44 son adultos, 6 subadultos y 1 de edad indeterminada. Esta elevada concentración de individuos adultos $(86,27 \%)$ es enormemente interesante por su contraste con la vecina necrópolis de la Bòbila Madurell y con las excavadas en los últimos años del Camí de Can Grau (La Roca del Vallès, Barcelona) o de Sant Pau del Camp (Barcelona), donde nunca se registraron únicamente enterramientos de adultos o infantiles.

Además de esta significativa concentración de sepulturas, en los alrededores de la necrópolis no se han descubierto estructuras domésticas, sean silos, fosas de desecho o hábitats. Todo ello, nos permite hablar de un área exclusivamente de uso funerario durante el inicio del IV milenio cal BC.

El excelente estado de conservación de buena parte de las estructuras funerarias y el cuidadoso

(5) Véase nota 3. 
registro estratigráfico y deposicional nos ha permitido elaborar una nueva y completa tipología de estos sepulcros. Los conocimientos que esta necrópolis nos ha aportado en relación a los procesos de construcción, los períodos de uso y amortización y los materiales empleados en su elaboración han sido fundamentales para conocer mejor las características de algunos tipos de enterramientos, desconocidos hasta el momento para este período cronológico. Nos referimos, por ejemplo, a la utilización de materiales perecederos en piel o madera para el cubrimiento de las sepulturas, así como a la identificación de grandes losas dispuesta horizontal y verticalmente sellando el acceso a las cámaras funerarias.

En general, se trata de sepulturas con formas y dimensiones heterogéneas producto del tipo de sepulcro construido y de su estado de conservación. Sobresalen por su espectacularidad los grandes sepulcros de planta rectangular con recorte superior y cámara funeraria central, así como las de planta rectangular con cueva frontal de dimensiones y profundidad considerables. En líneas generales presentan de media entre 1-2 m de profundidad, por 2-3 $\mathrm{m}$ de planta, en los casos más completos. También existen algunos sepulcros de dimensiones más reducidas, así como otros muy arrasados de los que únicamente se han preservado sus 20 y $50 \mathrm{~cm}$ basales. Estas sepulturas suelen localizarse en la parte más alta del paraje, más expuesta a los efectos de la erosión y de las actividades agrícolas. En general cabe decir que todas las estructuras han debido sufrir procesos erosivos que han provocado la pérdida de las partes superiores de los enterramientos, posiblemente entre 80 y $150 \mathrm{~cm}$.

El elevado número de estructuras complejas y el ingente volumen de material arqueológico que ha ofrecido Can Gambús-1 hacen de esta necrópolis una de las más completas que tenemos en el noreste de la Península Ibérica. En este trabajo presentamos un primer avance de la documentación obtenida y de los trabajos realizados. Queda mucho por hacer, en un conjunto funerario extremadamente complejo que requiere de la participación de numerosos especialistas y de un cuidadoso tratamiento estadístico de los datos (6).

(6) Las analíticas efectuadas hasta ahora en la necrópolis neolítica son las siguientes: material cerámico (Roig y Coll 2007, e.p., -véase nota 3-), paleoantropología (Villar, V.; Ruiz, J. y Subirà, M.E.: Estudi Antropològic de les restes neolítiques del jaciment de Can Gambús 1 (Sabadell, Vallès Occidental), juliol 2006. En J. Roig y J.M. Coll (dirs.): Memòria de la inter-

\section{NUEVOS ENTERRAMIENTOS PARA UNA NUEVA TIPOLOGÍA}

La identificación de sepulturas bastante intactas y la presencia de nuevos tipos de enterramientos con singulares sistemas de cobertura, nos ha permitido redefinir y completar la tipología que hasta el momento se había establecido para los sepulcros de fosa del Neolítico medio en el noreste peninsular [Pou y Martí 1995 (7); Martí et al. 1997]. Hemos establecido 5 tipos básicos en la necrópolis de Can Gambús-1 (Figs. 3 y 4):

Tipo A: estructuras funerarias de carácter monumental, formadas por un gran recorte superior de planta rectangular, configurando una repisa perimetral y una cámara funeraria central también de planta rectangular. Las dimensiones del recorte oscilan entre los $4-2,5 \mathrm{~m}$ de longitud y $\operatorname{los} 3-2,4 \mathrm{~m}$ de anchura. Las de la cámara funeraria central son proporcionadas: entre los 2,5 - 1,4 $\mathrm{m}$ de longitud y los 1,5 - 0,9 $\mathrm{m}$ de anchura, con una profundidad de unos $0,9-1,85 \mathrm{~m}$. Estos sepulcros se orientan según un eje noreste-suroeste (entre $60^{\circ}$ y $90^{\circ} \mathrm{NE}-270^{\circ}$ y $230^{\circ} \mathrm{SO}$ ). Se han documentado 11 inhumaciones individuales (23\%) (8), 7 masculinas, 3 femeninas y 1 de gé-

venció arqueolòica a Can Gambús 1 (Sabadell, Vallès Occ.), abril 2003 - desembre 2004 i agost 2006, Memória inédita depositada en el Servei d'Arqueologia de la Generalitat de Catalunya. Barcelona, julio 2008), material lítico tallado (Gibaja y Terradas 2008), material lítico pulimentado -hachas- (Pétrequin, P. y Vaquer, J.: Anàlisi i estudi de les destrals de pedra polida de Can Gambús 1 (Sabadell, Vallès Occ.). Estudio inédito entregado al Servei d'Arqueologia de la Generalitat de Catalunya. Barcelona, 2008), arqueofauna (Nadal, J.: Estudi de les restes de fauna del neolitic del jaciment de Can Gambús 1 (Sabadell, Vallès Occidental). En J. Roig y J.M. Coll (dirs.): Memòria de la intervenció arqueològica a Can Gambús 1 (Sabadell, Vallès Occ.), abril 2003 - desembre 2004 i agost 2006, Memória inédita depositada en el Servei d'Arqueologia de la Generalitat de Catalunya. Barcelona, julio 2008), malacología (Estrada, A.: "Estudi de les restes malacofaunístiques prehistòriques recuperades al jaciment de Can Gambús 1 (Sabadell, Vallès Occidental)". En J. Roig y J.M. Coll (dirs.): Memòria de la intervenció arqueològica a Can Gambús 1 (Sabadell, Vallès Occ.), abril 2003 - desembre 2004 i agost 2006, Memória inédita depositada en el Servei d'Arqueologia de la Generalitat de Catalunya. Barcelona, julio 2008), fitolitos (Juan, J. y Matamala, J.C.: "Estudi arqueobotànic (fitòlits, midons i fibres) i de residus en continguts de recipients i material lític de mòlta de Can Gambús 1 (Sabadell, Vallès Occidental), Campanya 2003”. En J. Roig y J.M. Coll (dirs.): Memòria de la intervenció arqueològica a Can Gambús 1 (Sabadell, Vallès Occ.), abril 2003 - desembre $2004 i$ agost 2006, Memória inédita depositada en el Servei d'Arqueologia de la Generalitat de Catalunya. Barcelona, julio 2008).

(7) Véase nota 1.

(8) Son las sepulturas: E110, E130, E167, E175, E176, E184, E228, E246, E668, E674 y E693. 


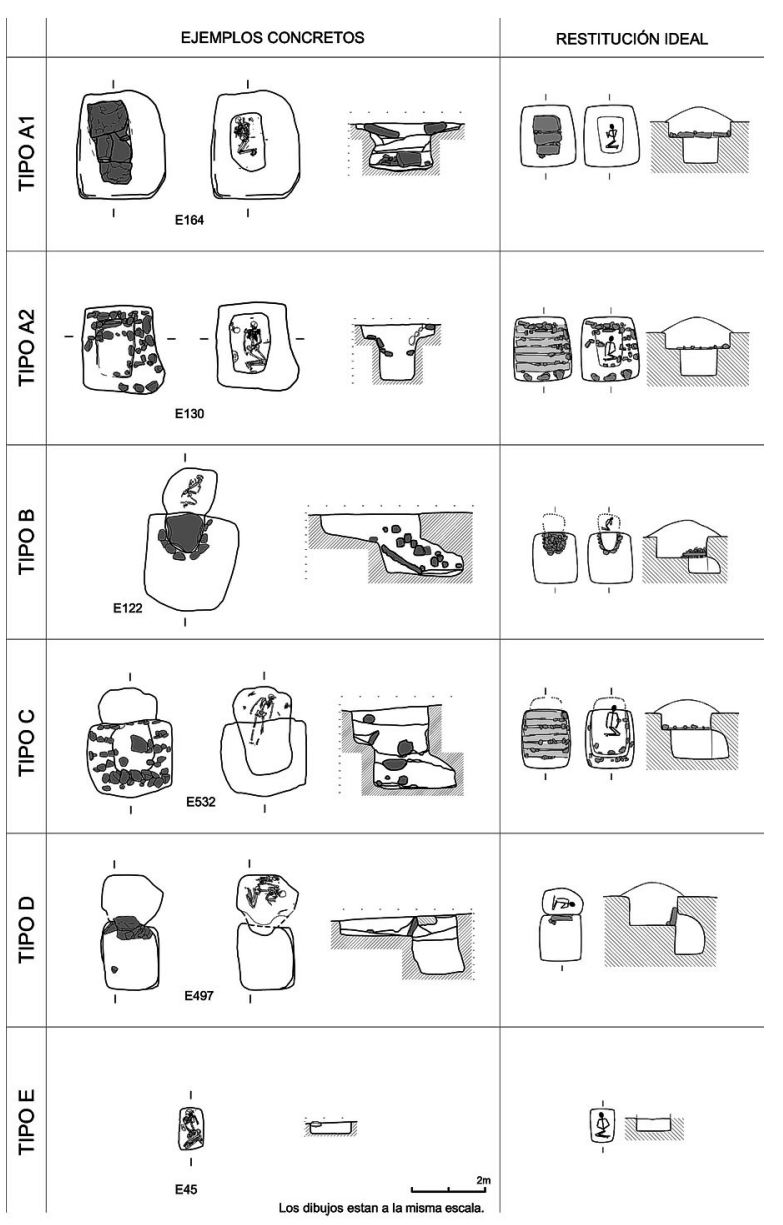

Fig. 3. Tipología de los sepulcros de fosa de la necrópolis del Neolítico medio de Can Gambús-1 (Sabadell, Barcelona).

nero indeterminado, siempre localizadas en el centro de la cámara funeraria, generalmente en decúbito supino con las piernas flexionadas y con una orientación que sigue más o menos el eje

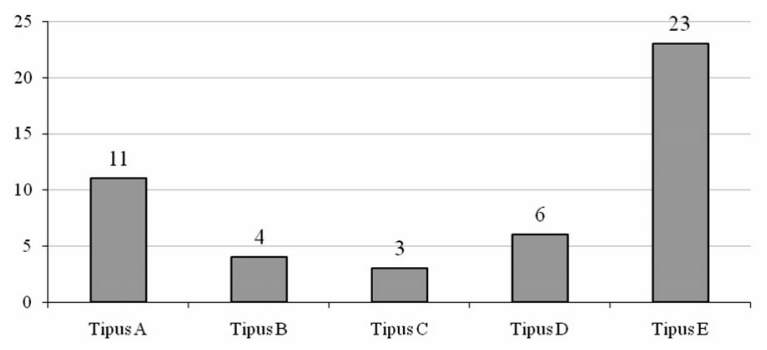

Fig. 4. Gráfico cuantitativo de los tipos de sepulcros de fosa de la necrópolis del Neolítico medio de Can Gambús-1 (Sabadell, Barcelona). central de la estructura. Todos los individuos estaban acompañados de un ajuar funerario numeroso y variado, destacando el de las sepulturas E130 y E110. Los enterramientos se concentran especialmente en la zona central de la necrópolis, a unos 197-198 m de altitud. Algunos como E228, E175, E176, E130 y E693 se encuentran muy cercanos entre sí. En base a la morfología de las cámaras se han distinguido dos variantes:

Tipo A1: sepulcros con cubierta horizontal realizada con grandes losas planas, apoyadas a ambos lados de la repisa del recorte superior cubriendo la cámara funeraria central (Fig. 5). Habitualmente tal cobertura está formada con dos o tres losas de conglomerado y caliza calzadas por algunas piedras de pequeño o mediano tamaño.

Tipo A2: cubierta de troncos y ramaje colocados horizontalmente, apoyados en la repisa superior y calzados por hiladas de piedras de pequeño y mediano tamaño. Sellaría el espacio funerario dejándolo vacío. Probablemente sobre la cubierta se dispondría alguna estructura de tierra y piedras en forma de túmulo.

Tipo B: Estructura funeraria monumental formada por un recorte superior con repisa de planta rectangular, que da acceso, mediante un pozo semicircular abierto en el lado noreste del recorte, a una cámara sepulcral subterránea frontal formando una pequeña cueva (Fig. 6). Su planta, irregularmente ovalada, mantiene la orientación del recorte superior. Una gran losa dispuesta horizontalmente y apoyada directamente sobre el perímetro de la boca del pozo cubre el acceso. En algunos casos el perímetro está delimitado y reforzado por una hilada de piedras y la losa está cubierta por una acumulación de piedras a modo de túmulo. Las dimensiones son parecidas a las del tipo A. La longitud total, entre el recorte superior y la cavidad funeraria, oscila entre los 3,7 $2,6 \mathrm{~m}$ y la anchura entre $2,3-1,5 \mathrm{~m}$.

Se conservan 4 estructuras de este tipo (9\%) (9), una de las cuales sólo con parte del recorte superior con repisa. Están dispuestas en el extremo noroeste de la necrópolis, con una orientación regular hacia el noreste $\left(35^{\circ}-50^{\circ} \mathrm{NE} \mathrm{y}\right.$ $215^{\circ}-230^{\circ} \mathrm{SO}$ ). Cada una contiene un individuo (1 masculino, 1 femenino y 2 alofisos) en decúbito supino con las piernas flexionadas y basculadas hacia uno de los lados. Están en el centro de

(9) Son las sepulturas: E122, E166, E186 y E442. 

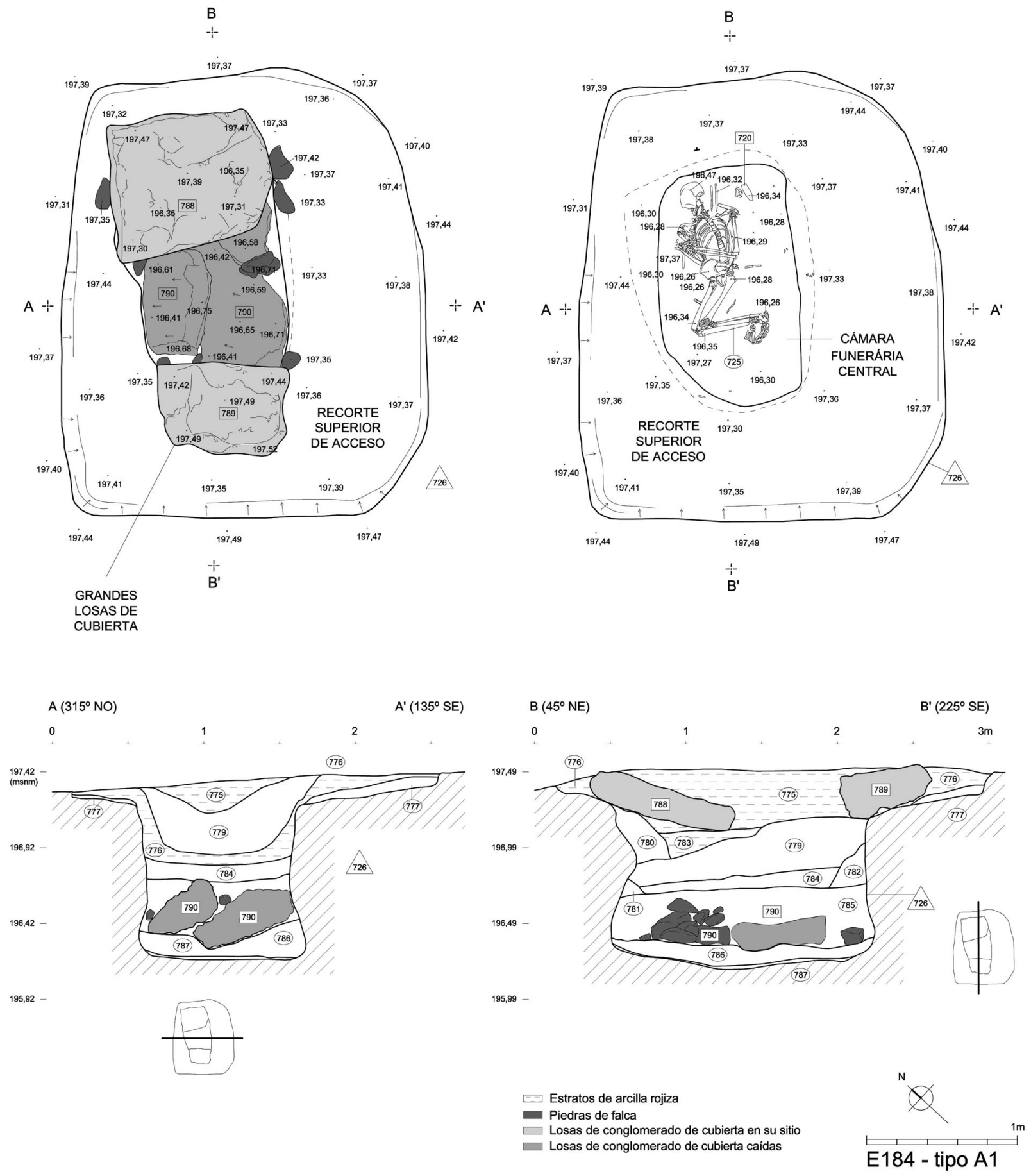

Fig. 5. Planta y sección del sepulcro E184 de Can Gambús-1 (Sabadell, Barcelona). Corresponde al Tipo A1 de pozo central y cubierta horizontal de grandes losas (J. Roig y J.M. Coll).

la cámara funeraria, acompañados de un ajuar variado y numeroso.

Tipo C: Estructura funeraria compleja y monumental formada por un recorte superior de planta rectangular con una repisa perimetral que genera otro recorte central rectangular a manera de acceso de grandes dimensiones. En su interior se abre frontalmente una pequeña cámara funera- 

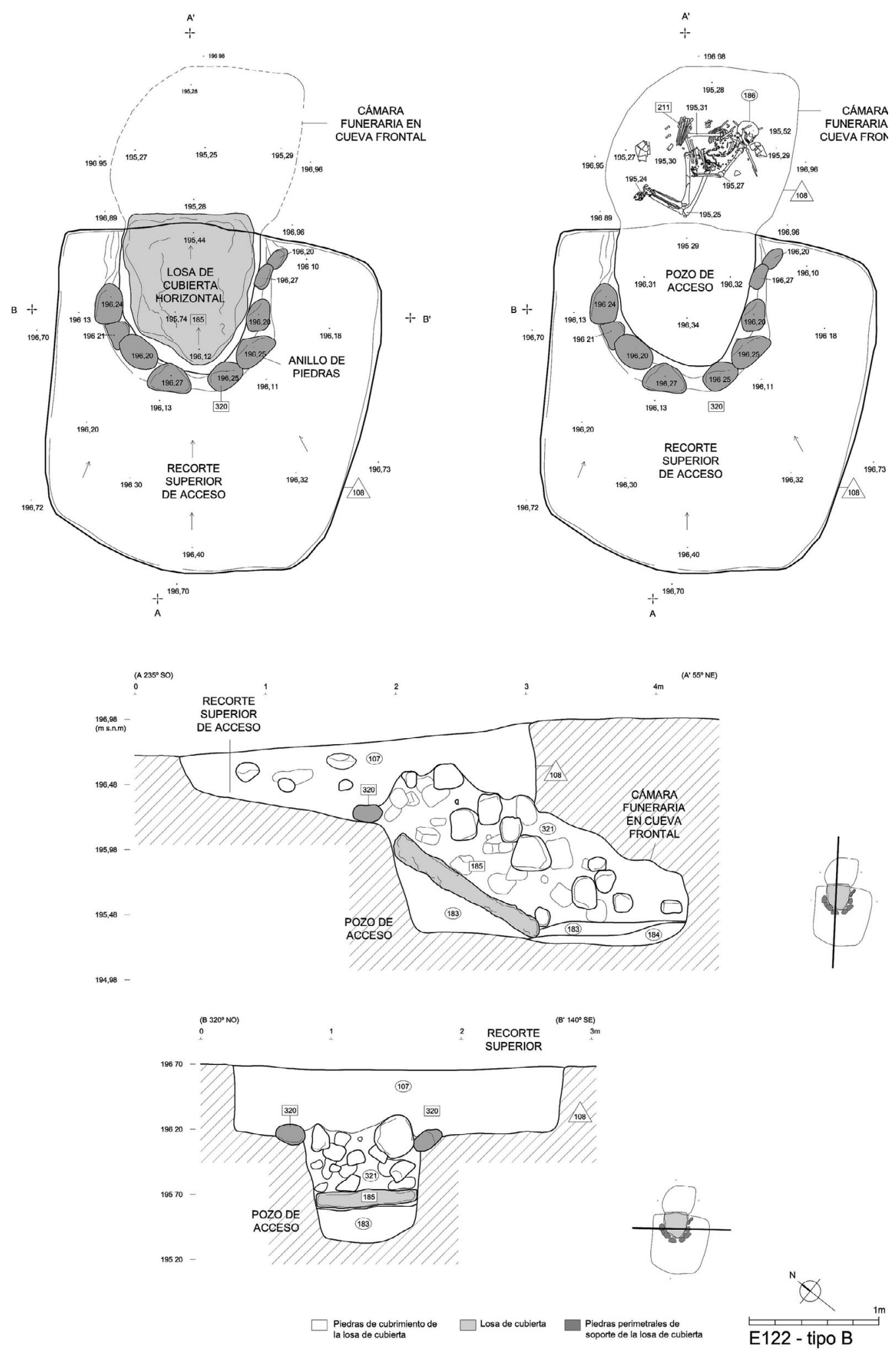

Fig. 6. Planta y sección del sepulcro E122 de Can Gambús-1 (Sabadell, Barcelona). Corresponde al Tipo $\mathrm{B}$ de cueva frontal y pozo de acceso con cubierta horizontal con una gran losa (J. Roig y J.M. Coll). 
ria. La cubierta sólo podría estar realizada con troncos de madera dispuestos horizontalmente sobre el gran espacio de acceso y apoyados sobre la repisa del recorte superior. Estos troncos estarían calzados por piedras de mediano tamaño y quizás recubiertos por alguna materia perecedera de naturaleza vegetal o animal (pieles) (Lám. II). A este respecto, hemos identificado un sedimento rojizo, con un alto contenido de materia orgánica entre y sobre las piedras empleadas para calzarlos. Finalmente, al ceder la estructura de troncos en un espacio vacío, el sedimento del túmulo se habría precipitado al interior del sepulcro.

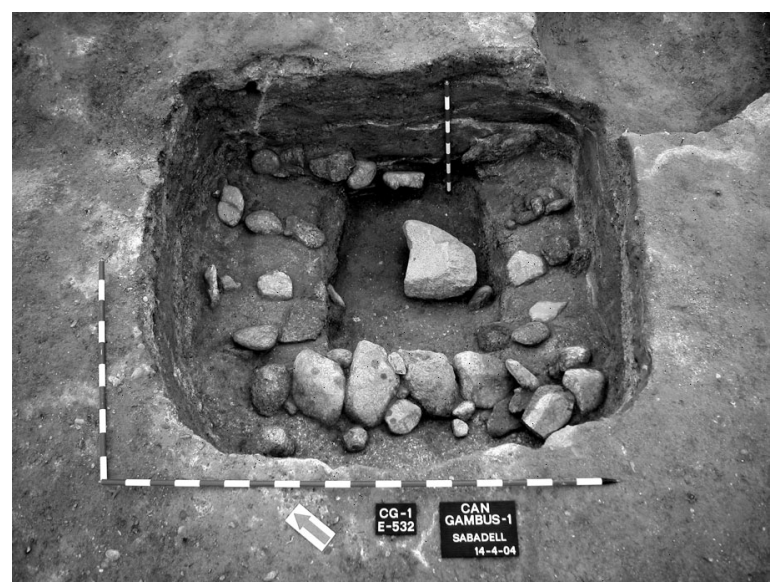

Lám. II. Foto del sepulcro E532 de Can Gambús-1 (Sabadell, Barcelona). Corresponde al Tipo $\mathrm{C}$ de cavidad frontal y gran cámara de acceso con cubierta horizontal de troncos calzados con piedras (J. Roig y J.M. Coll).

Los 3 sepulcros documentados (6\%) (10) se encuentran en el extremo sudoeste de la necrópolis. Son sepulturas con medidas regulares de 2,8 $3 \mathrm{~m}$ de longitud y 2,2 - 2,5 $\mathrm{m}$ de anchura, que muestran una orientación también homogénea $\mathrm{NE}-\mathrm{SO}$ (entre los $35^{\circ}-60^{\circ} \mathrm{NE}$ y los $200^{\circ}-220^{\circ}$ $\mathrm{SO})$. Un individuo masculino, uno femenino y otro alofiso fueron enterrados en posición de decúbito supino, con las piernas estiradas (en dos casos) o flexionadas ( 1 caso), y situados en el extremo del ábside de la cámara funeraria. Todos ellos están asociados a ajuares compuestos por numerosos y variados materiales.

Tipo D: Estructura funeraria compleja de tipo monumental, formada por un recorte superior de

(10) Son las sepulturas: E112, E161 y E532. planta rectangular en cuyo lateral se abre un pequeño pozo vertical que va a dar a una cavidad sepulcral. La pequeña abertura frontal del pozo de acceso aparece sellada por losas de conglomerado colocadas verticalmente y estabilizadas por piedras más pequeñas. La cámara de planta ovalada está orientada perpendicularmente al eje del recorte superior (Fig. 7). Las 6 estructuras $(13 \%)(11)$ atribuibles a este tipo D se sitúan en la periferia de la necrópolis, tres en el lado oeste y otras tres en el norte, siguiendo un eje de orientación noreste-suroeste. Sus dimensiones son bastante regulares, pero únicamente dos, localizadas en la parte más baja de la necrópolis, conservan la estructura entera con el recorte superior. Tienen unos 3,20 m de longitud por 1,7 - $2 \mathrm{~m}$ de anchura. Las dimensiones de la cámara sepulcral oscilan entre los 1,8 - 1,1 m de longitud y los 0,9 - 1,35 m de anchura. Este tipo de inhumación se diferencia del de los otros tipos en la presencia de sepulcros dobles: 3 estructuras contienen inhumaciones dobles y 3 inhumaciones individuales. De los 9 individuos identificados 6 son masculinos, 1 femenino y 2 indeterminados. Se disponen con la misma orientación que la cámara sepulcral, es decir, perpendiculares al recorte superior de acceso. Todos están acompañados de un ajuar bastante escaso, destacando especialmente la ausencia de ornamentos de variscita.

Tipo E: Reúne los sepulcros que, por su grado de erosión, presentan una estructura funeraria simple con una cámara única de planta rectangular o elíptica, y mayoritariamente con la cubierta desaparecida. Al habernos sido imposible atribuirlos a ninguno de los tipos anteriormente descritos, se ha optado por englobarlos en una categoría tipológica particular. Debemos tener presente que varias de estas sepulturas podían corresponder a algunos de los tipos más monumentales, pero tampoco desechamos la posibilidad de que otras tuvieran, efectivamente, esta estructura más simple de planta rectangular. De hecho, en ciertas zonas de la necrópolis aparecen juntos ambos tipos de enterramientos, en ocasiones tan solo a unos escasos $50 \mathrm{~cm}$ de distancia. $\mathrm{Si}$ hubiera existido algún tipo de erosión o arrasamiento habría afectado por igual a ambos sepulcros, a no ser que entre ellos existiera una diferencia cronológica y que el arrasamiento hubiera

(11) Son las sepulturas: E137, E208, E221, E497, E515 y 

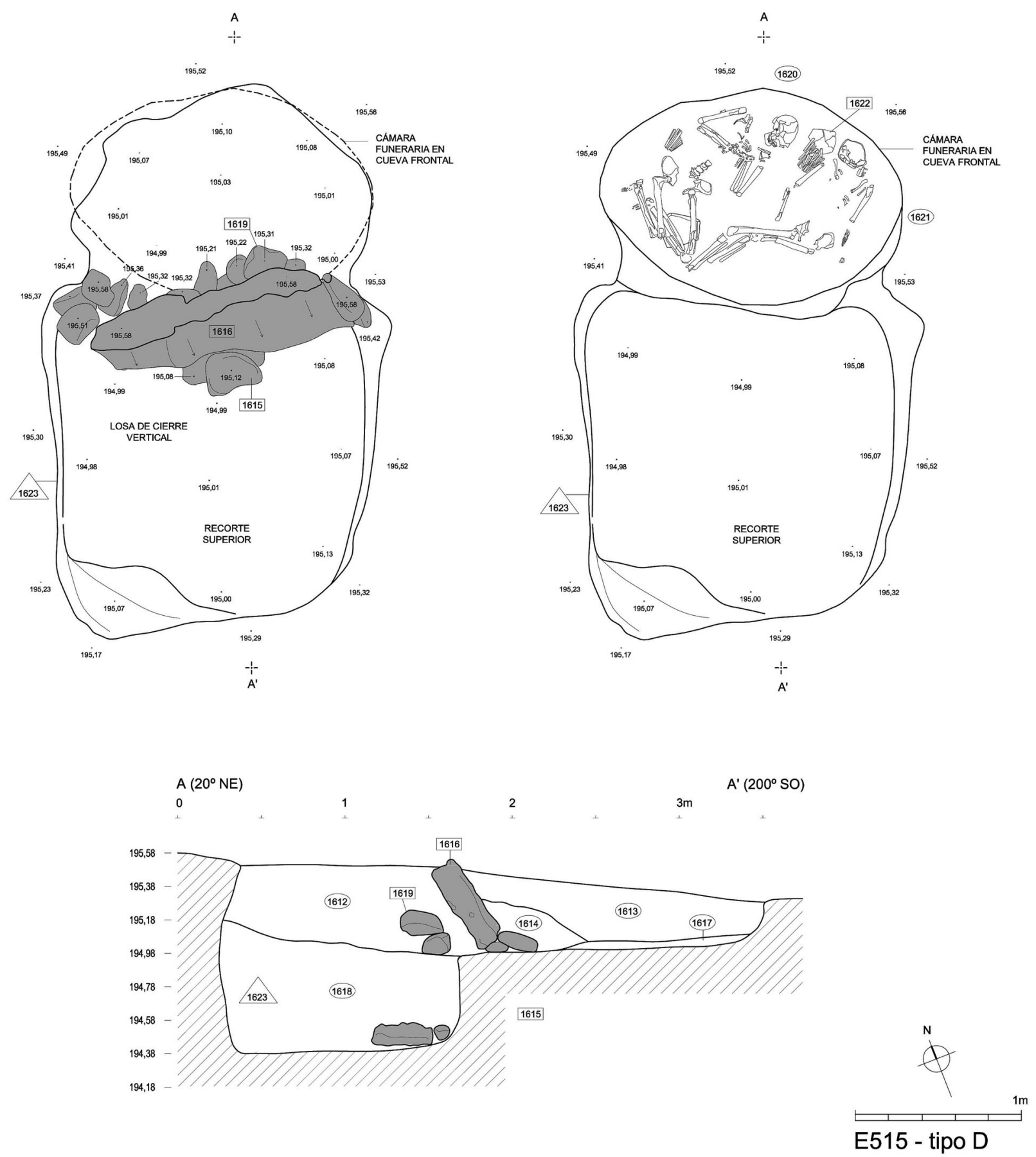

Fig. 7. Planta y sección del sepulcro E515 de Can Gambús-1 (Sabadell, Barcelona). Corresponde al Tipo D de cavidad funeraria frontal con apertura de acceso frontal y sellado vertical de losas. Este tipo presenta dos inhumaciones conjuntas (J. Roig y J.M. Coll). 
actuado sobre los más antiguos. Las sepulturas son fosas simples de planta rectangular de entre $90-130 \mathrm{~cm}$ de longitud, $60-80 \mathrm{~cm}$ de anchura y una profundidad conservada entre $15-60 \mathrm{~cm}$. Las 23 estructuras (49\%) (12) se extienden por la parte central de la necrópolis, en la zona más alta de la loma, con una orientación noreste-suroeste. Hemos registrado un conjunto de 24 individuos ya que una de las sepulturas es doble (E247): 7 son masculinos, 8 femeninos y en 9 casos no ha sido posible determinar el sexo. Existen diferencias notables entre los ajuares, que refuerzan la hipótesis de que algunos podrían ser sepulcros complejos arrasados y otros enterramientos morfológicamente más sencillos. Algunos han ofrecido ajuares muy ricos (por ejemplo la E70) en cantidad, calidad y diversidad de piezas, en tanto que otros contenían algún fragmento de cerámica, un punzón o algún elemento de malacología aislado. Tres de ellos carecían de ajuar (E168, E516 y E534).

A modo de resumen, estas sepulturas en fosa son estructuras funerarias complejas y monumentales que se vertebran a partir de un gran recorte superior de planta rectangular y un pozo de acceso a una cámara funeraria inferior donde se ha inhumado uno o dos individuos. Estarían selladas por una cubierta que mantendría el espacio inferior cerrado y vacío de tierra como lo indican los propios sistemas de cobertura, la dinámica estratigráfica, la disposición de los huesos de los individuos inhumados y los saqueos fechados en época neolítica. La dinámica estratigráfica y postdeposicional, así como las características tafonómicas de los esqueletos nos han permitido plantear diversas cuestiones:

- Esta nueva tipología debe considerarse preliminar a la espera de la finalización de determinados estudios y analíticas, así como de la realización de un mayor número de dataciones radiocarbónicas.

- En determinados sepulcros (sepulcros E112, E162 y E176) hemos detectado la intrusión puntual a las cámaras mortuorias después de haberse practicado la inhumación gracias a las remociones de ciertas partes esqueléticas, en especial de la zona torácica y el cuello, aún en estado de semidescomposición. Ello implica que se llevaron a

(12) Son las sepulturas: E45, E70, E111, E113, E115, E116, E127, E162, E163, E168, E170, E171, E174, E179, E180, E223, E243, E247, E441, E516, E534, E664 y E665. cabo en un momento posterior y cercano al momento de la inhumación. Pensamos que dichas remociones pueden estar asociadas al saqueo intencionado de elementos de ajuar como los collares o pulseras elaboradas con cuentas de variscita ya que, en estas tumbas, sólo hemos encontrado cuentas esparcidas sin conexión. También hemos apreciado una alteración de la cubierta, reflejada en la caída de los troncos o de algunas de las losas que sellaban la cámara.

- En las estructuras de cubrimiento hemos detectado túmulos formados por tierras y/o piedras dispuestas por encima del espacio superior de la sepultura que está cubierto con losas o troncos.

- La reutilización de determinados sepulcros se observa en la inhumación simultánea de dos individuos en el sepulcro E515, y en la inhumación sucesiva de otros dos en los enterramientos E247, E497 y E580.

- El uso de ciertos elementos constructivos perecederos desaparecidos se constata por las cubiertas de madera o el posible revestimiento de las paredes y las soleras.

- El uso de estructuras internas de material también perecedero provoca, como veremos, los "efectos de parada" en los esqueletos como consecuencia de la presencia, en su día, de lechos, paredes o mobiliario funerario o, quizás, del uso de pieles o materias vegetales a modo de mortajas que explicaría la hipercontracción de algunos cuerpos.

- Determinados elementos de ajuar y ciertas prendas que llevaban los inhumados, desafortunadamente, no han llegado hasta nosotros, aunque en algunas sepulturas (E184 o E110) haya sido sugerido su empleo por la presencia de unos finos estratos (de unos $2-4 \mathrm{~cm}$ ), inmediatamente por debajo del individuo inhumado y de su ajuar, con abundantes restos de ocre rojo y carbón. Tales restos podrían ser los residuos de materiales empleados para cubrir los cuerpos de los inhumados (pieles) o para evitar su contacto con el suelo, empleando algún tipo de mobiliario funerario similar a lechos o ataúdes de madera.

\section{CRONOLOGÍA DE LA NECRÓPOLIS DE CAN GAMBÚS-1}

Hasta el momento se han realizado cuatro dataciones de $\mathrm{C} 14$ sobre restos óseos humanos procedentes de cuatro sepulcros de Can Gambús-1, efectuadas en el Laboratorio de Datación por Ra- 
diocarbono de la Universitat de Barcelona [Mestres 2007 (13)], que han proporcionado los siguientes resultados:

- UBAR-900 (E-110): 4850 180 BP (cal BC $3800-3495,86,3 \%$ a $2 \sigma$ - fecha calibrada experimental: cal BC 3644). Individuo masculino adulto joven.

- UBAR-901 (E-167): 4980 \pm 40 BP (cal BC $3812-3656,79,0 \%$ a $2 \sigma$ - fecha calibrada experimental: cal BC 3766 y cal BC 3721). Individuo masculino adulto.

- UBAR-902 (E-246): 4865 \pm 40 BP (cal BC $3714-3628,78,5 \%$ a $2 \sigma$ - fecha calibrada experimental: cal BC 3648). Individuo femenino adulto.

- UBAR-903 (E-515-Ind. 2): 4570 600 BP (cal BC 3385-3090, 79,7 \% a $2 \sigma$ - fecha calibrada experimental: cal BC 3356). Individuo masculino adulto 2 .

Las tres primeras fechan enterramientos del Tipo A2 (E110, E167, E246), situados en la parte central de la necrópolis, con un ajuar típico de los sepulcros de fosa (variscita, sílex melado, vasos cerámicos, industria ósea, etc.). Su horquilla cronológica es muy homogénea y corta, aproximadamente unos 120 años, entre el 3766 y el 3644 cal BC.

La última datación pertenece al sepulcro E515, del Tipo D, que contiene una inhumación doble, con escaso ajuar y sin variscita ni sílex melado. Su datación (3356 cal BC) rejuvenece aproximadamente 300 años este enterramiento respecto a los tres del Tipo A2. De esta manera, y aunque sea de manera provisional, observamos una cierta evolución cronológica de algunos tipos de sepulcros en la necrópolis de Can Gambús-1 donde las sepulturas de pozo central del Tipo A serían más antiguas que las del Tipo D.

Estas dataciones se ajustan perfectamente a las ya ofrecidas por otros contextos funerarios del Neolítico medio en Cataluña como la Bòbila Madurell y el Camí de Can Grau (Gibaja 2003; Martí et al. 1997; Martín 2009). En estos momentos estamos a la espera de recibir los resultados de nuevas dataciones pertenecientes al resto de los tipos sepulcrales. Ello nos permitirá definir la cronología de funcionamiento de la necrópolis, completando la seriación tipológica de los diferentes sepulcros de fosa de Can Gambús-1.

(13) Mestres, J.S.: Datació per radiocarboni de material ossi d'origen humà procedent de Can Gambús 1 (Sabadell, Vallès Occ.). Informe Inédito depositado en el Museu d'Història de Sabadell y en Arrago S.L. Sabadell, mayo 2007.

\section{ANÁLISIS ANTROPOLÓGICO}

Los 51 individuos documentados en Can Gambús-1 presentan, en general, un buen índice de preservación (un $66,67 \%$ del grupo muestra un índice superior al $75 \%$ ) aunque su estado de conservación deficitario ha dificultado un estudio más a fondo de los individuos. Esto se refleja en las escasas ocasiones en las que se ha podido realizar el estudio tipológico craneal.

Un $80,40 \%$ de los individuos se dispusieron en la tumba en decúbito supino, un 7,84\% (3 derecho y uno izquierdo) en decúbito lateral y en un $11,76 \%$ no se ha podido establecer su posición por la escasa representación del individuo. En los enterramientos dobles, los individuos estaban dispuestos en decúbito supino, uno al lado del otro, salvo en una ocasión donde uno se disponía sobre el otro. En un $50 \%$ de los enterramientos las extremidades inferiores del cadáver se flexionaban hacia arriba, cediendo hacia un lado u otro del eje central del tronco al iniciarse el proceso de descomposición. En algún caso esta posición llegó a mantenerse. En cambio las extremidades superiores fueron dispuestas sin modelo definido sobre la pelvis, estiradas paralelamente al cuerpo o situadas sobre el tórax. Cuando ha sido posible valorarlo, el cráneo estaba dispuesto ligeramente hacia un lado con la cara orientada hacia el resto del cuerpo. Parece que la cabeza se habría colocado sobre algún elemento a modo de cojín, de naturaleza perecedera, ya que éste no se ha conservado.

Al proceder a la limpieza del material óseo se observaron restos de ocre en diversas regiones esqueléticas que, en el cráneo, ocupan tanto el neurocráneo como la mandíbula, las órbitas y el malar. Un mismo individuo puede presentar ocre en distintas zonas sin que se haya podido asociar a un sexo o grupo de edad concreto. Es probable que esta práctica se realizara sobre un número mayor de individuos y que el paso del tiempo y el mal estado de conservación de los restos dificultara su conservación.

\subsection{Determinación demográfica del grupo}

Se ha podido asignar la edad a todos los individuos menos a uno por su baja representatividad esquelética. Un 86,27\% de individuos corresponden a población adulta, y el 11,77\% a un grupo de edad mayor de 18 años, perteneciente o no a la 
etapa adulta. En estos últimos sólo se ha podido utilizar el método de desgaste del esmalte dental de Brothwell (1987) y todos ellos presentaban tercer molar (Tab. 1). La franja de edad más representada (52\% de la población) corresponde a individuos entre 26 y 45 años (adulto joven y adulto). Incluso 4 individuos ( $8 \%$ de la población) alcanzaron los 60 años de edad, demostrando que la población gozaba de buenas condiciones de vida.

Cabe destacar la ausencia de individuos infantiles cuya representatividad en poblaciones antiguas oscila habitualmente entre un 30-60\% (Chimenos 1990). Parece que se está ante una necrópolis o un sector en el que únicamente se inhumó a una parte de la población. Ello refleja, probablemente, una sociedad que no consideraba por igual a todos sus integrantes, sin que sepamos con exactitud si este grupo pertenecía a una élite o trataba diferencialmente al conjunto de la población infantil y juvenil.

En cuanto al sexo, 21 de los individuos pertenecen al masculino $(41,18 \%), 15$ al femenino $(29,41 \%), 8$ son alofisos $(15,68 \%)$ y 7 indeterminados $(13,73 \%)$. La relación de masculinidad resultante, 140, es superior a los 100 - 105 hallados en poblaciones actuales. No obstante los 15 individuos sin sexo diagnosticado podrían alterar esta relación. Los datos, por tanto, no permiten decidir la utilización mayoritaria o no de esta necrópolis por parte de un único sexo, a diferencia de lo que acontece con la edad.
Por último, subrayamos que 3 de los 4 individuos seniles son de sexo masculino y el cuarto de sexo indeterminado, hecho que indica que las condiciones de vida para el sexo femenino fueron más duras, probablemente debido a su condición de madres, lo que reduce su esperanza de vida.

\subsection{Descripción tipológica de la población}

Clásicamente las poblaciones prehistóricas e históricas se han descrito a partir de la tipología de los cráneos. Los restos craneales de los individuos de Can Gambús-1 son incompletos y no permiten una descripción de este tipo. No obstante varias medidas sobre el esqueleto postcraneal permiten describir al grupo desde otro punto de vista, su robustez o gracilidad asociada a la actividad laboral.

Respecto a la extremidad superior, el índice diafisario del húmero, tanto derecho como izquierdo, manifiesta euribraquia en la población masculina y femenina. La morfología es redondeada en la mayoría de los húmeros en relación con una baja actividad del brazo. En cuanto al antebrazo, los tres cúbitos indican platolenia. Los valores se corresponden con una morfología poco redondeada del cúbito. A pesar de la baja representatividad, y a falta de más información, se podría decir que el esfuerzo muscular del antebrazo en la población estudiada es superior al descrito en la parte superior del brazo, como resultado de un movimiento de aducción del antebrazo. En la

\begin{tabular}{|c|c|c|c|c|c|c|c|}
\hline & & Masculinos & Femeninos & Alofisos & Indet. & $\mathbf{n}$ & $\%$ \\
\hline Juvenil & 13 a 25 años & & 3 & 2 & 1 & 6 & $11,77 \%$ \\
\hline \multicolumn{2}{|c|}{ Subadultos totales } & & & & & 6 & $11,77 \%$ \\
\hline Adulto joven & 26 a 35 años & 7 & 3 & 2 & 1 & 13 & $25,49 \%$ \\
\hline Adulto & 36 a 45 años & 6 & 5 & 1 & 1 & 13 & $25,49 \%$ \\
\hline Maduro & 46 a 60 años & & 3 & 2 & & 5 & $9,80 \%$ \\
\hline Senil & $>$ de 61 años & 3 & & & 1 & 4 & $7,84 \%$ \\
\hline Adultos indet. & & 5 & 1 & 1 & 2 & 9 & $17,65 \%$ \\
\hline \multicolumn{2}{|l|}{ Total adultos } & & & & & 44 & $86,27 \%$ \\
\hline \multicolumn{2}{|l|}{ Indeterminados } & & & & 1 & 1 & $1,96 \%$ \\
\hline & & $\begin{array}{c}41,18 \% \\
\quad 21\end{array}$ & $\begin{array}{c}29,41 \% \\
\mathbf{1 5}\end{array}$ & $\begin{array}{c}15,68 \% \\
\mathbf{8}\end{array}$ & $\begin{array}{c}13,73 \% \\
7\end{array}$ & 51 & $100 \%$ \\
\hline
\end{tabular}

Tab. 1. Distribución de la población de Can Gambús-1 (Sabadell, Barcelona) según los distintos grupos de edad y sexo. 
actividad diaria del grupo, no intervendría la porción superior de la extremidad mientras que el antebrazo se movería hacia el plano medio del cuerpo.

En relación a las extremidades inferiores, el índice de platimeria indica que los fémures son platiméricos o hiperplatiméricos en su mayoría, es decir, aplanados anteroposteriormente como consecuencia de una fuerte actividad de los músculos del tercio proximal. En el índice pilástrico, calculado también en el fémur, los valores son más variables. Los hombres presentan pilastra entre débil y fuerte, con valores superiores a los de los individuos femeninos. Este índice valora el grado de desarrollo de la línea áspera, lugar donde se insertan diversos músculos del muslo. Los valores obtenidos indican un esfuerzo débil como consecuencia de un movimiento no muy severo en el tercio medio del muslo. El índice cnémico indica un mayor porcentaje de tibias mesocnémicas poco aplanadas y platicnémicas con aplanamiento transversal. Contrariamente, en el sexo femenino dominan las tibias euricnémicas. G. Olivier (1960) relaciona las tibias platicnémicas con índices pilástricos elevados en poblaciones prehistóricas. Esta situación no se asemeja a la que encontramos en la población neolítica de Can Gambús-1, donde se aprecia un esfuerzo más notable de la musculatura insertada en el tercio proximal del fémur respecto a la musculatura de los tercios medio y distal.

\subsection{Estado de salud de la población}

En la población de Can Gambús-1 se han observado diversos traumatismos. El más frecuente, en cuatro individuos, en el antebrazo. Este tipo de traumatismos suele estar asociado a caídas y por tanto se puede relacionar con el estilo de vida y el tipo de actividad desarrollada por la población.

El 43,14 \% de la población superó los 35 años por lo que se pudiera pensar en la probabilidad de encontrar una frecuencia relativamente alta de patologías osteoarticulares. A pesar de ello sólo se ha observado en un $5 \%$ de los individuos evidencias de lesiones osteofíticas y aplastamiento de algunas vértebras cervicales en la columna vertebral.

En cuanto a los procesos infecciosos únicamente se ha evidenciado una ligera periostitis en un individuo senil, afectando al húmero y a la tibia.
Los datos dentales también aportan información respecto al estado de salud de la población. Sin embargo, características dentales como el retroceso alveolar o la presencia de lesiones fistulosas no han podido valorarse por el mal estado de conservación del soporte óseo. Hay caries en el $6 \%$ de las piezas dentales, valor cercano al ya descrito en la población neolítica catalana (10\%). Según E. Chimenos (1990) la caries afecta a un $43 \%$ de los individuos al menos en una pieza. La pérdida dental ante mortem es de un $8 \%$. Normalmente se asocia a los molares inferiores y corresponde en su mayoría a los individuos de mayor edad. Asimismo, se ha contemplado la presencia de cálculo dental en aproximadamente un $6 \%$ del grupo. La observación macroscópica de la dentición ha permitido valorar en cinco individuos un desgaste dental anómalo, con la formación ocasional de un canal orientado mesiodistalmente en los incisivos y caninos. Este desgaste iba acompañado de la presencia de manchas posiblemente taninos, cuyo origen es vegetal. Se trata pues de un desgaste no causado por la alimentación sino por un uso extraalimentario de la boca. Están en curso los análisis químicos del origen de las manchas y un estudio del tipo de desgaste mediante el microscopio electrónico.

A modo de resumen, el estudio antropológico nos permite decir que:

- El depósito primario del cadáver está sin colmatar de tierra y el individuo se encuentra en posición mayoritariamente de decúbito supino $(80 \%)$.

- El grupo está formado por individuos de ambos sexos, mayores de 17 años y con una elevada esperanza de vida.

- La actividad laboral relacionada con el movimiento de aducción del antebrazo es la posible causante de los traumatismos. Asimismo los signos musculares de la extremidad inferior se pueden vincular a una musculatura desarrollada como consecuencia de la marcha.

- Algunas patologías óseas se corresponden con signos artrósicos en individuos de edad adulta y senil.

- Las caries se constatan en pocas piezas, pero en prácticamente la mitad de los individuos. $\mathrm{Su}$ etiología probable es la alimentación.

- La población disponía de un relativo buen estado de salud. 
- Cinco individuos presentaban desgaste dental extraalimentario asociado a la utilización de la boca para trabajar probablemente materias vegetales, como demuestra la presencia de taninos en los dientes.

\section{APROXIMACIÓN PALEOTAFONÓMICA A LAS SEPULTURAS DE CAN GAMBÚS-1}

El nombre "Cultura de los Sepulcros de Fosa" sugiere sepulturas bastante minimalistas, contrariamente a la concepción que se tiene de las tumbas megalíticas. Sin embargo la elaboración de las fosas requiere una importante inversión de trabajo. Los estudios de V. Renom en la Bòbila Madurell revelaron, desde los años cuarenta, la existencia de enterramientos complejos realizados en el suelo, con cavidades en los laterales o incluso selladas con grandes bloques de conglomerado (Serra Ráfols 1947). No obstante, debemos esperar a la excavación de la primera tumba de Can Soldevila en los años 80 para contar con una descripción precisa de la arquitectura (Costa et al. 1982). R. Pou y M. Martí [1995 (14)] definieron la complejidad de las construcciones, al menos para una parte de la tipología sepulcral del Neolítico catalán.

En la excavación de Can Gambús-1, un análisis tafonómico como el presentado en este artículo ha sido posible en el marco de unas condiciones excepcionales de conservación y registro. Este tipo de análisis, desarrollado desde los años 70 en la investigación francesa, tiene como objetivo reconstruir la sepultura inicial a partir de los vestigios documentados en la estructura arqueológica (Leroi-Gourhan 1975; Duday 1995). Para este trabajo nosotros nos hemos centrado en tres enterramientos que, no sólo nos permiten identificar y ejemplificar los procesos de descomposición de los inhumados en espacios vacíos, sino también poner las bases para una verdadera reconstrucción del dispositivo sepulcral. Tales enterramientos corresponden a los Tipos A, B y C de la tipología establecida para Can Gambús-1. Nosotros presentamos aquí una visión general de los resultados de los análisis tafonómicos obtenidos en dos de estas sepulturas, antes de plantear ciertas hipótesis sobre la tercera.

(14) Véase nota 1.

\subsection{Las sepulturas E137 y E442}

La sepultura E137 pertenece probablemente al tipo D, si bien buena parte del pozo de acceso ha desaparecido por la erosión. El sujeto inhumado reposa sobre su espalda, con los miembros flexionados, según una orientación sureste-noroeste, y la cabeza erguida. Los codos doblados están separados del tronco, la mano izquierda se sitúa sobre el vientre y la derecha por debajo del tórax. Los miembros inferiores se han desplazado hacia el lado izquierdo y las rodillas están flexionadas. El pie izquierdo se encuentra sobre el eje general del cuerpo y el pie derecho está ligeramente desplazado lateralmente (Fig. 8).

El esqueleto está íntegramente estirado. Las únicas piezas en desequilibrio son el conjunto cráneo-facial y la rótula derecha. Asimismo, se aprecian abundantes dislocaciones, muchas de ellas acompañadas de una transgresión del volumen inicial del cadáver. Es el caso por ejemplo de la clavícula izquierda, los codos y el antebrazo derecho, la parte derecha de la pelvis, la rodilla izquierda y la pierna derecha. La localización de estas dislocaciones en la mayoría de las partes del cuerpo, indica que el cadáver se descompuso en un espacio vacío. El mantenimiento de la rótula refleja su apoyo en su día contra la pared de la fosa. La posición desequilibrada del cráneo responde a un fenómeno puntual, como la existencia de una irregularidad en el fondo de la tumba o, más probablemente, de un soporte hoy desaparecido, confeccionado en alguna materia perecedera que debió disgregarse después de la colmatación de la sepultura.

Estas dislocaciones no responden únicamente a que haya un espacio vacío. Si el desplazamiento de la clavícula izquierda ha sido provocado por el encogimiento del hombro, la separación de los dos huesos del antebrazo derecho debe explicarse por algún movimiento sobre uno de ellos. La migración del hueso coxal derecho no ha podido ocurrir sobre un suelo plano. La situación es idéntica para la rodilla izquierda y posiblemente para el peroné derecho. El desplazamiento del hueso coxal derecho, y con él el del fémur, se explica por la existencia de una pendiente o un espacio vacío por debajo de esta parte del cuerpo durante la descomposición. El resto de la pelvis se encuentra finalmente en el mismo nivel. Todo ello supone que hubo un espacio vacío durante la descomposición, debajo de una gran parte del cuer- 


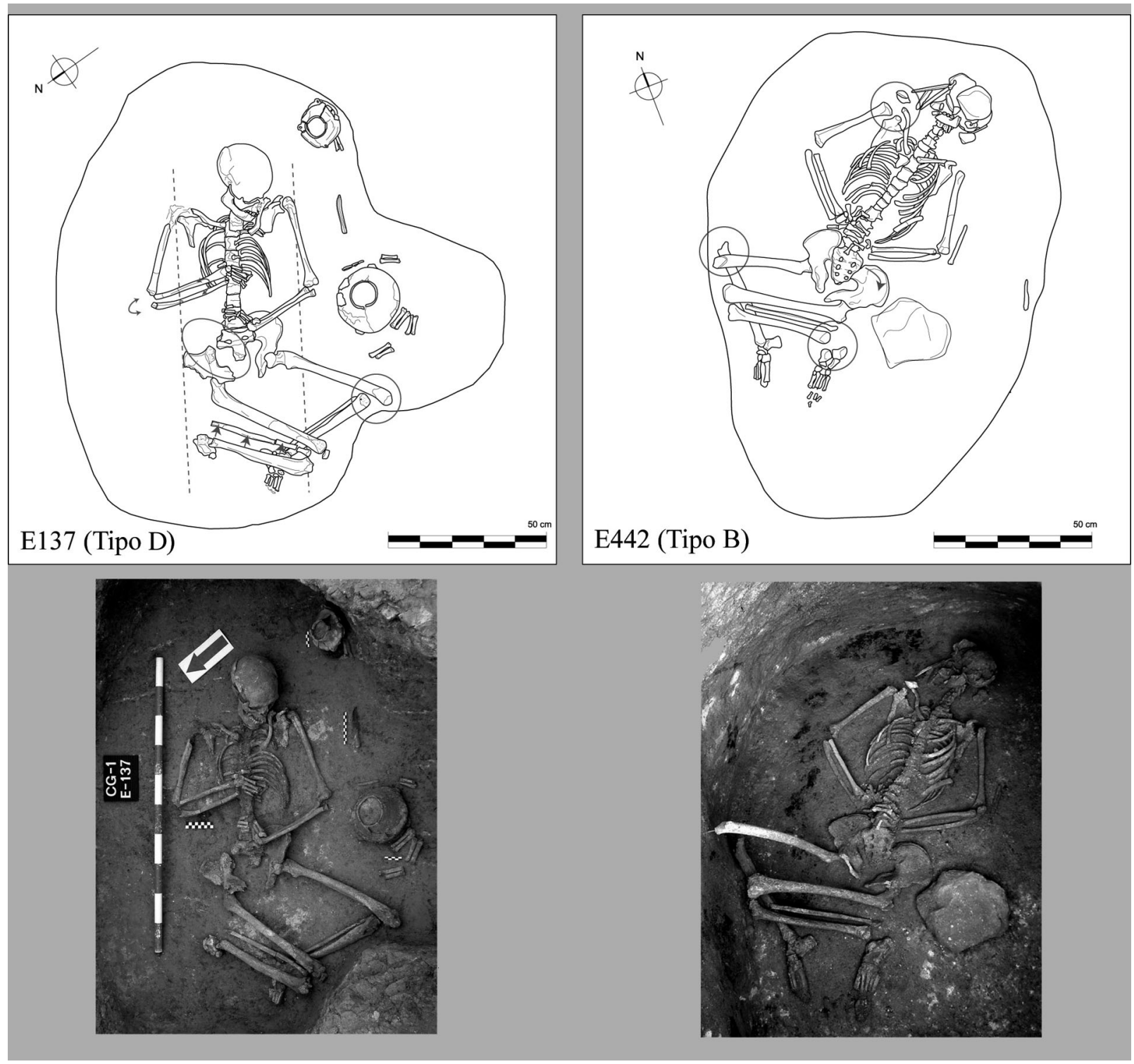

Fig. 8. Vista completa de los sepulcros E137 y E442 de Can Gambús-1 (Sabadell, Barcelona). Se señalan las principales dislocaciones de los esqueletos. Para la tumba E137, las líneas de puntos corresponden a los límites del continente en el que estaba depositado el cadáver (J. Roig, J.M. Coll y Ph. Chambon).

po. La disyunción de las otras articulaciones, especialmente de la rodilla izquierda y la pierna derecha ¿es imputable a este mismo fenómeno? La de las rodillas testimonia un hundimiento, si bien las roturas corresponden ante todo a un descenso progresivo tras una posición sobreelevada.

Pocos elementos quedan por reseñar en relación a la planificación de las inhumaciones. Vista la estructura sepulcral, es evidente que el cadáver no reposaba sobre el fondo de la fosa, si no sobre una banqueta o una especie de camilla o litera, una estructura fija sobre la que se depositó el cuerpo. Las rodillas estaban plegadas y sobreelevadas, la cabeza estaba erguida, mantenida por un soporte y el ajuar se encontraba claramente separado del cuerpo y no dentro o sobre tal banqueta.

La sepultura E442 se inscribe en el tipo B. El sujeto reposa sobre la espalda, con los miembros flexionados y con una orientación este-oeste. La cabeza se sitúa sobre el lado derecho, mirando 
hacia el norte. Los miembros superiores presentan una tendencia simétrica. Los codos están separados del cuerpo, las manos juntas en el abdomen y los dedos están entrelazados. Los miembros inferiores estaban flexionados y las rodillas elevadas. Los pies están situados en el eje del cuerpo, el izquierdo a unos $15 \mathrm{~cm}$ de las nalgas y el derecho a unos $20 \mathrm{~cm}$ (Fig. 8).

El esqueleto está situado claramente en posición plana. Los huesos en desequilibrio son raros o inexistentes. A excepción de los pies, las conexiones preservadas conciernen a las articulaciones, como a las de la cadera, o a los ligamentos intervertebrales. El volumen inicial del cadáver ha sido quebrantado a nivel del hombro derecho, por la clavícula, así como en la parte inferior del cuerpo alrededor del hueso coxal izquierdo y de las extremidades inferiores. El caso del cráneo es menos evidente. Estos desplazamientos fuera del volumen del cuerpo testimonian un espacio vacío durante la descomposición. Si esos espacios vacíos repercuten tanto en el hombro, como en la pelvis o en todos los miembros inferiores, su amplitud reflejada en la rotura de las rodillas, indica que se trata de un vacío global desde sus inicios. No obstante, la descomposición en un espacio vacío no es suficiente para explicar todas las dislocaciones identificadas. Si el desplazamiento de la clavícula derecha parece muy importante, los movimientos registrados en la parte inferior del esqueleto van más allá de su simple caída después de la disgregación de los ligamentos. El caso de los miembros inferiores no se resuelve únicamente por la caída de los huesos en elevación. Así mientras la rodilla derecha se ha fracturado, la tibia y el peroné han seguido unidos, el tobillo se ha mantenido y el pie ha rotado sin generar ninguna dislocación. De hecho la caída de los miembros inferiores da lugar, en el lado izquierdo, al basculamiento del pie en vista lateral (parcial). Los dos pies se encontraban inicialmente en plano, en el mismo eje que el cuerpo. En este sentido, a pesar de la diferencia entre el lado derecho y el izquierdo, los tobillos se habrían mantenido más tiempo que las rodillas.

En un registro diferente la simple caída del hueso coxal izquierdo no justifica su separación de la pelvis. Si bien hay un deslizamiento hacia el sur del hueso coxal, se encuentra finalmente a la misma altitud que el resto de la pelvis, por lo que tal desplazamiento no ha podido producirse sobre un suelo plano. Ello implica que debió existir un soporte entre el cuerpo y el suelo cuya disgregación ha creado las condiciones que han provocado el desplazamiento del hueso coxal.

La descomposición en espacio vacío deja sin explicación el mantenimiento de los pies en conexión, a no ser que imaginemos un relleno precoz de esta parte de la tumba o una inversión del orden clásico de la disgregación de las articulaciones. Estas conexiones testimonian la presencia de un dispositivo de protección de los pies, a modo de calzado. La hipótesis de un inhumado con calzado significa que probablemente estamos frente a una persona que estaba vestida.

Identificar todo el acondicionamiento sepulcral es imposible, aunque hemos apreciado la posición desequilibrada del sujeto en la tumba y la preservación de abundantes residuos negros en el fondo y en las paredes de la cámara. Ello sugiere que existe una preparación específica alrededor del cadáver que nos habla de que fue transportado en un dispositivo móvil. Los residuos orgánicos indican, efectivamente, el empleo de materias perecederas en la preparación de la cámara sepulcral.

\subsection{Descifrar los acondicionamientos sepulcrales: interrogantes en torno a la tumba E167}

En relación a la tipología, las tumbas consideradas como complejas se realizaron mediante un cuidadoso proceso de preparación cuyas características definiremos. Señalaremos cinco puntos principales en relación con la adecuación del difunto a la estructura funeraria de la sepultura E167, perteneciente al Tipo A (Fig. 9).

El sujeto no se depositó directamente en el fondo de la tumba, sino en el seno de un continente. La posición variable de ese continente en el interior de la cámara indica que era móvil. Por lo tanto, parece evidente que sirvió para transportar al difunto hasta la tumba ¿De qué se trata exactamente? La forma debía ser rectangular y estrecha, lo que obligaba a mantenerle con las rodillas flexionadas. Los rebordes debían ser bajos, al menos sobre los laterales largos, ya que los codos estaban por encima de ellos y las rodillas habían finalmente salido hacia afuera.

El ajuar es impresionante no sólo por su abundancia, sino también por la calidad y la rareza de los materiales. No obstante, estamos únicamente 


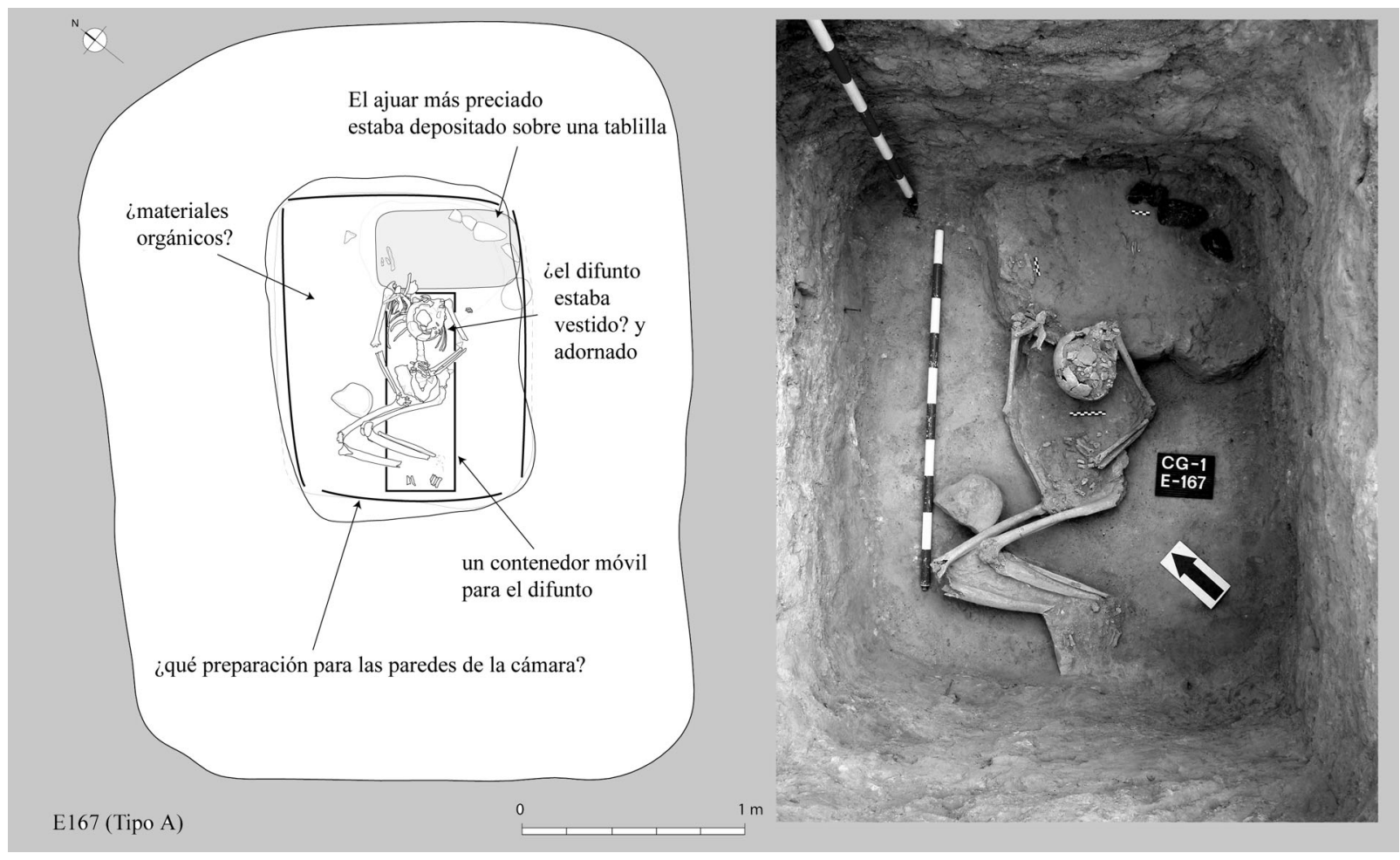

Fig. 9. Vista completa del sepulcro E167 de Can Gambús-1 (Sabadell, Barcelona). Hipótesis en relación a la organización de la tumba (J. Roig, J.M. Coll y Ph. Chambon).

ante las reliquias que han llegado a conservarse, ya que faltan todos los objetos de o sobre materias orgánicas. Así podemos considerar que el hacha estaba enmangada o que los instrumentos de huesos estaban almacenados dentro de una especie de funda o saco (15). Una prueba aún más concluyente son los elementos geométricos agrupados, ensartados probablemente en flechas, que seguramente se depositaron junto al inhumado en un carcaj, quizás también con el arco. El conjunto del ajuar se encuentra detrás del sujeto, pero no se sitúa directamente en el fondo de la sepultura. El nivel tan regular en el que reposa el hacha, los núcleos y una parte de la industria ósea indica la presencia de un soporte por debajo, a modo de banqueta o tablilla. Puede tratarse de un elemento del ajuar -a modo de mueble- o de un acondicionamiento de la propia cámara.

(15) En la tumba E137 los pares de falanges animales situados alrededor del vaso son los últimos vestigios de una piel que cubría o se encontraba sobre dicho vaso. Al lado de estos objetos subsiste un residuo orgánico producto de una materia que ha desaparecido totalmente. Próximo a los núcleos de la tumba E167 también hay testimonio de un residuo negro alargado.
La construcción de la cámara testimonia un cuidado y una inversión de trabajo importante, pero no existe señal de su preparación. Sólo la cobertura de la tumba ha podido ser reconstruida, principalmente a partir de los elementos de calzado (piedras y troncos) caídos en el fondo del pozo de acceso. Aunque la descomposición del cadáver, que tuvo lugar en un espacio vacío, nos permite dilucidar acerca de la existencia de una cobertura, el conjunto de indicios tafonómicos no nos permite apreciar el grado de complejidad de la estructura funeraria. Si consideramos la regularidad de la estructura, con sus paredes ortogonales y perfectamente verticales, podemos sin dificultad suponer que la parte superior fue recubierta con tableros de madera, revestimientos, etc.

En definitiva, las sepulturas de Can Gambús-1 representan un descubrimiento excepcional, también en la percepción de las tumbas que nos imponen. No podemos observarlas como simples construcciones donde los muertos han sido rápidamente enterrados. La tumba es uno de los actores principales de los funerales. En los sepulcros de fosa es evidente que los preparativos están re- 
lacionados con la posición social o el estatus privilegiado del difunto.

\section{LOS AJUARES FUNERARIOS}

De los 47 sepulcros de la necrópolis, hasta 44 ofrecen un rico y diversificado ajuar funerario. En los 3 restantes, adscritos al Tipo E, no hay restos de ajuar, probablemente como consecuencia de su estado de conservación y el alto grado de arrasamiento, especialmente en los sepulcros E168 y E534. La relevancia cualitativa de la gran mayoría de los ajuares permite un estudio muy completo de la cultura material del Neolítico medio en el noreste de la Península Ibérica y nos ofrece importantes datos sobre las comunidades humanas de este período, en especial en relación a sus costumbres funerarias. Gran parte de estos estudios sobrepasan los contenidos de este artículo, destinado a una presentación general del contenido de los ajuares salvo el material cerámico y lítico, estudiados ya en profundidad.

En Can Gambús-1 hay un total de 617 elementos arqueológicos (16), entre material lítico tallado (núcleos, láminas, puntas y geométricos de sílex) y utillaje macrolítico (hachas y molinos), vasos cerámicos enteros y fragmentados, utillaje óseo (punzones, agujas, plaquetas, etc.), restos de macrofauna y malacofauna y elementos ornamentales (contabilizando de manera unitaria los collares y brazaletes de variscita).

Los elementos del ajuar se encuentran generalmente en la mitad superior de la cámara funeraria, dispuestos alrededor y/o sobre el cuerpo de los individuos, especialmente próximos a su cabeza y a su mitad superior y, más raramente, cerca de los pies. Se han documentado restos cerámicos en 27 sepulcros, acompañando tanto a individuos masculinos como femeninos. Del total de 59 elementos, 51 son vasos enteros o de perfil conservado. De éstos, 36 son determinables a nivel formal $(71 \%)$ y sólo 15 son indeterminables (29 \%). Es decir, en algunos casos se dejaron junto a los inhumados partes de vasos fracturados

(16) Esta cantidad de elementos de ajuar podrá verse modificada cuando se realicen los trabajos de restauración de determinados materiales, en especial de los punzones de hueso, ya que a menudo fueron encontrados agrupados formando paquetes y se extrajeron conjuntamente para después tratarlos en el laboratorio. que quizás se emplearon como soportes para calzar algún elemento perecedero.

Hay instrumentos líticos tallados en 39 enterramientos. Entre los 203 restos, por su cantidad y calidad, sobresalen núcleos, láminas, geométricos y puntas elaboradas casi exclusivamente en sílex melado. Los núcleos aparecen habitualmente en pares o tríos, en la zona próxima al cráneo o en la mitad superior de la tumba, jamás en los pies. Las puntas y los geométricos se agrupan a uno de los lados del individuo indicando, como hemos dicho, su posible enmangue en los astiles dentro del carcaj. Este es el caso del sepulcro E176 con 3 puntas de flecha y 8 geométricos de sílex agrupados con el extremo apuntando hacia abajo en la zona de los pies, a la derecha del individuo (Lám. III).

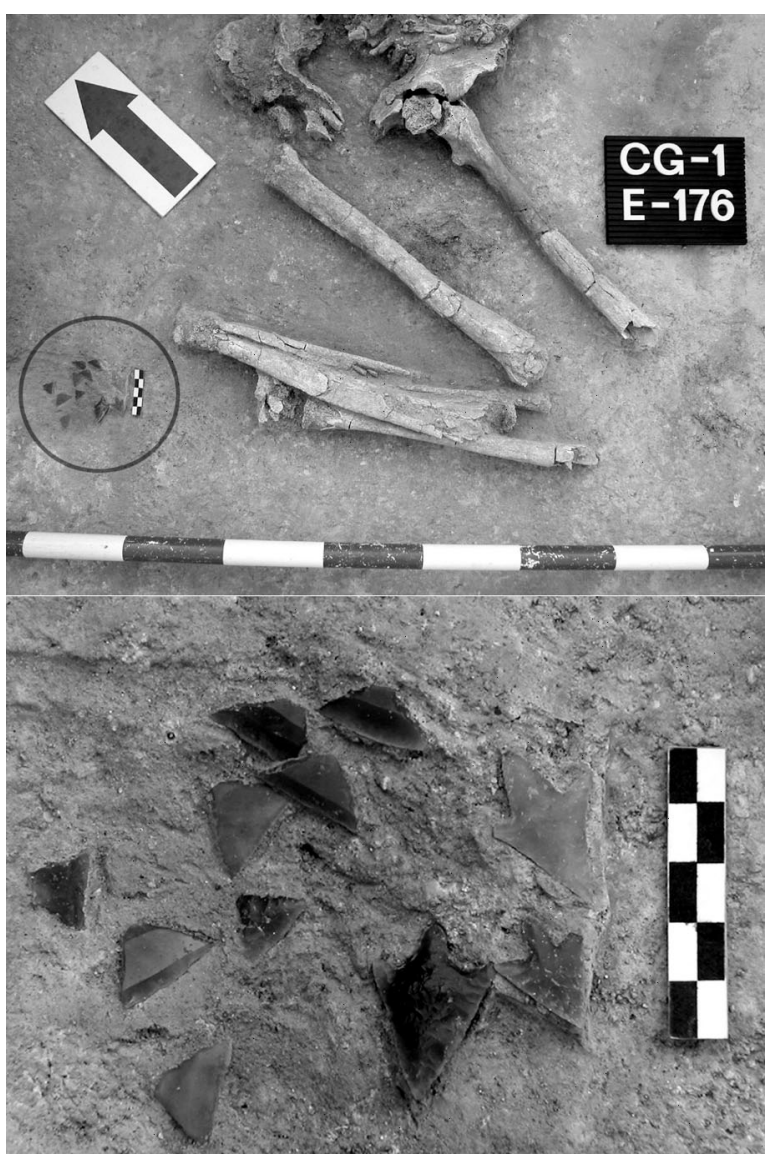

Lám. III. Agrupación de 3 puntas de flecha y 8 geométricos de sílex con el extremo apuntado hacia abajo situada en la zona de los pies del individuo del sepulcro E176 de Can Gambús-1 (Sabadell, Barcelona) (J. Roig y J.M. Coll). 


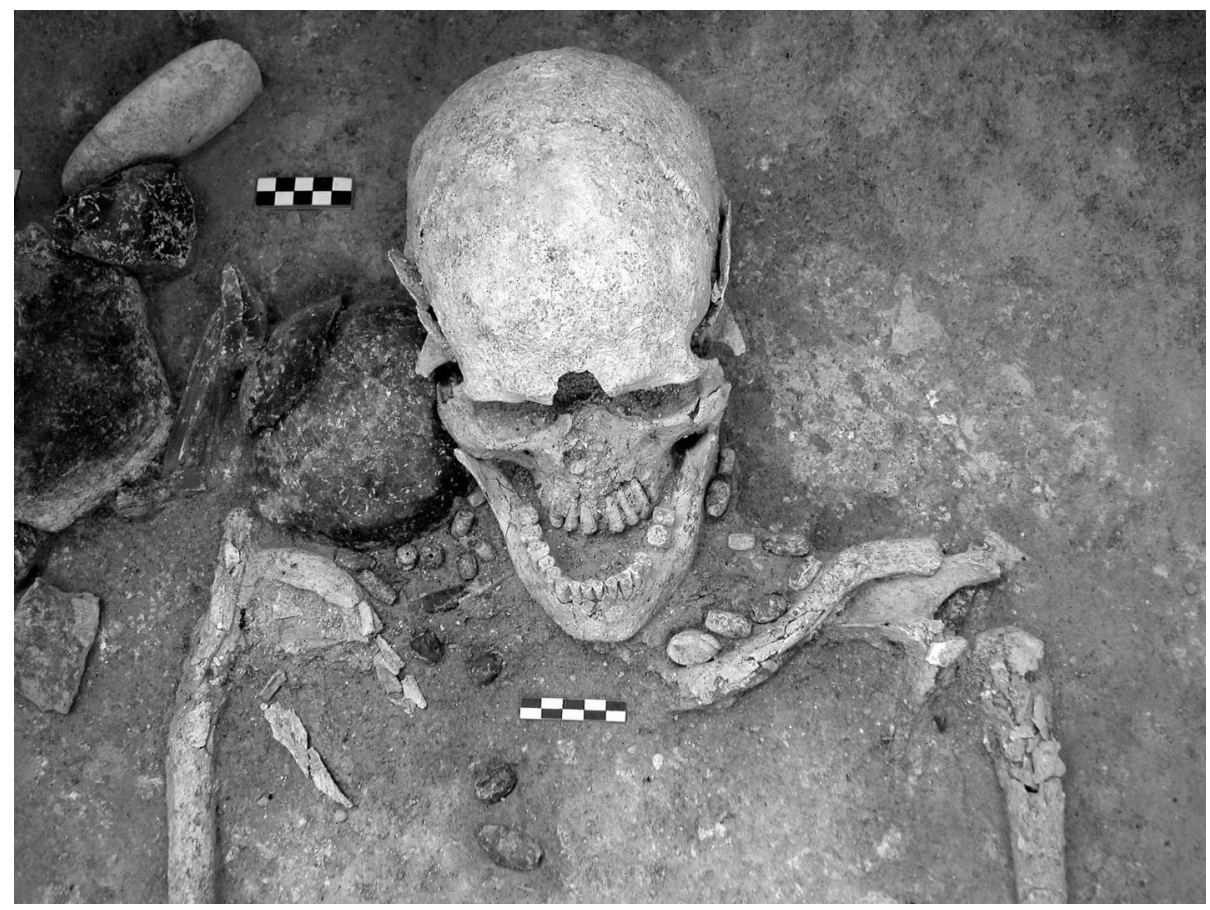

Lám. IV. Detalle de la mitad superior del individuo del sepulcro E668 de Can Gambús-1 (Sabadell, Barcelona) con parte de su ajuar funerario. Se observa el collar de variscita en disposición original alrededor del cuello. (J. Roig y J.M. Coll).

Los 18 instrumentos de piedra pulida se han documentado en 15 sepulcros. Mayoritariamente son hachas pulidas, muchas asociadas a núcleos de sílex. Las 14 hachas proceden de 12 sepulcros: 10 con una sola hacha y 2 con dos. Según el análisis petrológico efectuado dos ejemplares son eclogitas de posible origen alpino [Petrequin y Vaquer 2008 (17)].

El utillaje macrolítico tan sólo se localiza en dos sepulcros del Tipo E (E45 -individuo alofiso- y E163 -individuo femenino-): 4 elementos de molino (dos bases fijas con su parte móvil). El análisis de los fitolitos de la base y de la mano del molino del sepulcro E45 ha permitido identificar restos de tejido epidérmico de almorta (Lathyrus cicera) y almidones de tipo Lathyrus y Triticeae (cereales tipo trigo/cebada) [Juan y Matamala 2008 (18)].

Los instrumentos óseos proceden de 31 sepulturas y, a la espera de los trabajos de su restauración, completan un conjunto de 244 útiles. La

(17) Véase Pétrequin y Vaquer en nota 4.

(18) Véase Juan y Matamala en nota 4. mayoría son punzones agrupados en paquetes (entre 4 y 20) al lado de los individuos.

Los elementos de ornamento se han hallado en 16 sepulcros: 620 cuentas de variscita de diferente tipología (cilíndricas, cilíndricas tubulares, bitroncocónicas o de barril, etc.) que forman $10 \mathrm{co-}$ llares, 4 brazaletes, 1 dispositivo/collar votivo y 15 cuentas sueltas. Asimismo, se ha registrado un collar con 1.644 cuentas de esquisto y 10 cuentas sueltas atribuidas a un segundo collar. El estudio de este material ornamental se encuentra en curso (Lám. IV).

Los 41 restos de fauna de vertebrados aparecieron en 11 enterramientos. Destacan especialmente las falanges de Ovis aries dispuestas en pequeños grupos o aisladas, halladas en 6 de estos sepulcros. También se asocian diferentes especies en un mismo contexto. Es el caso del sepulcro E130 con un fragmento vaciado de asta de Cervus elaphus y un canino de Sus sp., o bien del fragmento basal de asta tallada de Cervus elaphus junto a dos colmillos de Sus sp. de la sepultura E161. Los otros restos registrados en la necrópolis son extremidades inferiores (metacarpianos y metatarsianos) de un Sus sp., un incisivo de Bos 
taurus y un fragmento medial de costilla de un mamífero de talla mediana [Nadal 2008 (19)].

La malacofauna marina está presente en 5 sepulcros con 5 piezas que presentan diferentes tratamientos. Así se han documentado tres bivalvos, concretamente un Glycymeris glycymeris con restos de ocre (tumba E161), un Glycymeris sp. (enterramiento E174) y un Cerastoderma edule (sepulcro E228). Las otras dos piezas corresponden a dos gasterópodos de la especie Phalium saburon utilizados como elementos de ornamento, ya que presentan dos perforaciones ligeramente cónicas (sepulturas E221 y E442) [Estrada 2008 (20)].

Diversos sepulcros contienen restos de material mineral, por lo general, ocre de color rojo intenso, que podrían estar asociados a elementos perecederos (pieles, tejidos, madera, ...) que acompañaban al difunto. También formaban parte del ajuar sedimentos de diferente consistencia y color de los que se han tomado muestras para determinar su naturaleza.

\subsection{El registro cerámico}

Está muy bien representado en los ajuares de los inhumados. Hay vasos cerámicos en 27 de las 47 tumbas de Can Gambús-1, 51 de ellos completos o de perfil conservado. En general, la cocción fue reductora irregular, lo que confiere a las pastas una coloración muy diversa con tonalidades grises, negras, marrones, anaranjadas y rojizas. Incluyen un desgrasante de tamaño mediano o grande caracterizado de visu por la presencia de cuarzo y mica esencialmente. No obstante, sería necesario efectuar los análisis arqueométricos correspondientes.

El modelado a mano es irregular, con un alisamiento simple, no siempre demasiado cuidadoso $\mathrm{y}$, salvo un caso, sin decoración, ya sea incisa o aplicada. Esta ausencia de decoraciones es una característica distintiva de los recipientes de este período, que contrasta con las precedentes del Neolítico antiguo Cardial, con decoración impresa, o con las siguientes del Neolítico final, con decoraciones plásticas y aplicadas. La excepción es un vaso esférico de bordes rectos, ligeramente entrados hacia el interior, labios de sec-

(19) Véase Nadal en nota 6.

(20) Véase Estrada en nota 6. ción cuadrangular y fondo cóncavo redondeado (CG1-243-555-5), con restos de un asa de cinta y hasta 7 lengüetas cónicas conservadas, aplicadas en paralelo por debajo del borde. Este recipiente globular es, por tanto, un elemento muy singular dentro de la necrópolis.

De entre los 51 vasos completos o de perfil conservado hemos determinado 36 vasos desde un punto de vista morfológico, siendo posible identificar 7 grupos formales o tipos básicos:

- Tipo 1: vaso hemisférico (NMI: $9=25 \%$ ) con el cuerpo igual o inferior a $180^{\circ}$ de abertura, de bordes rectos o salientes y labios de sección redondeada o rectangular. Los fondos siempre son redondeados y, en algunos casos, irregulares debido a su elaboración manual.

- Tipo 2: vaso hemisférico carenado (NMI: $5=14 \%$ ) compuesto por una mitad superior troncocónica cóncava invertida y otra inferior hemisférica, unidas por una carena bien marcada. El borde, siempre saliente, presenta únicamente labios apuntados y el diámetro de la boca es siempre superior al diámetro máximo de la carena. Los fondos son cóncavos y ligeramente aplanados. Todos presentan un asa aplicada a la carena, tubular (3 casos) o de cinta (2) (Lám. V).

- Tipo 3: vaso esférico cerrado (NMI: $8=$ $22 \%$ ) con un grado de cierre del cuerpo superior a los $180^{\circ}$ Los bordes son reentrantes y con el labio saliente en algunos casos. El fondo es cóncavo y puede aparecer ligeramente aplanado.

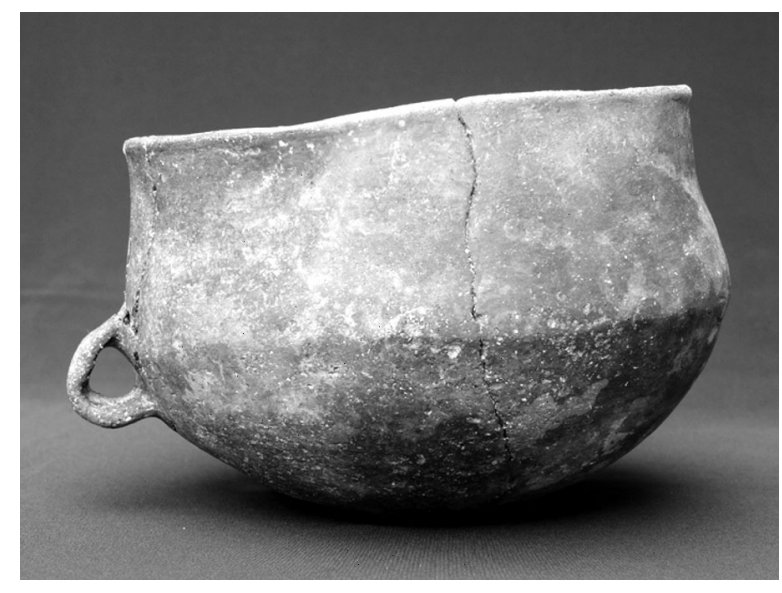

Lám. V. Vaso de cerámica carenado procedente del ajuar del sepulcro E110 de Can Gambús-1 (Sabadell, Barcelona). El diámetro de la boca es $13,4 \mathrm{~cm}$ y su diámetro máximo 14,2 cm. La altura de la pieza es 9,3 cm (J. Roig y J.M. Coll). 
- Tipo 4: vaso esférico carenado (NMI: $4=$ $14 \%$ ) formado por un cono truncado superior y un cuerpo hemisférico inferior, unidos mediante una carena bien marcada. Los bordes son reentrantes y presentan, en los casos conservados, dos asas de cinta opuestas en la mitad superior del cuerpo.

- Tipo 5: vaso esférico carenado con cuello diferenciado cóncavo (NMI: $4=11 \%$ ), compuesto por un cuerpo truncado de paredes cóncavas en la mitad superior y un cuerpo hemisférico en la mitad inferior, unidos por una carena bien marcada. El cuello, cóncavo, no se diferencia del borde, siempre recto o ligeramente convergente. Estos vasos llevan cuatro asas tubulares verticales, dispuestas radialmente bajo la línea de la carena. Este tipo se ha vinculado generalmente con la presencia de la cultura neolítica Chassey del Languedoc en el noreste peninsular (Llongueras et al. 1981). Sus paralelos más cercanos los encontramos en la necrópolis del Camí de Can Grau (Martí et al. 1997).

- Tipo 6: vaso de boca rectangular (NMI: 5 = $11 \%)$ con cuerpo de sección rectangular y fondo cóncavo aplanado, diferenciado mediante unas carenas suaves. Tienen una única asa aplicada entre la línea que marca la inflexión del fondo y la mitad superior del vaso. Son ampliamente conocidos en la literatura arqueológica como "vasos de boca cuadrada" (Ripoll y Llongueras 1963) y se han relacionado con la cultura neolítica de Lagozza del norte de Italia (Maluquer 1950; Muñoz 1965). Los encontramos también en las necrópolis catalanas de Bòbila Madurell (Serra-Ràfols 1947; Muñoz 1965), el Camí de Can Grau (Martí et al. 1997) o en la tumba 2 de Sant Julià de Ramis (Tarrús 1981).

- Tipo 7: vaso hemisférico con un pie macizo cónico (NMI: $1=3 \%$ ), identificado a partir de un único recipiente (E70-310-1). El cuerpo superior es hemisférico, de paredes curvadas, labio apuntado y el pie inferior troncocónico, de base circular plana $(43 \mathrm{~mm})$. Presenta dos singulares perforaciones cilíndricas paralelas formando un ángulo de $45^{\circ}$ que atraviesan la base del pie. Su acabado es alisado simple y la cocción es oxidante. Estamos ante una forma singular e inédita en los registros cerámicos del Neolítico medio en el noreste de la Península Ibérica. Únicamente existe un posible fragmento paralelizable, documentado en las minas prehistóricas de Gavà, pero desconocemos la forma que tendría el vaso (Villalba et al.
1986: 93, Fig. 44, n. ${ }^{\circ}$ 11). La pieza de Can Gambús-1 podría asimilarse formalmente a un candil o quemador o, quizás, a un vaso tipo copa. En este sentido, presenta parte de un lateral fuertemente descamado y con señales de haber sufrido un mayor desgaste por el uso.

Reunimos bajo la categoría de "tipos no determinables" un último grupo o categoría cerámica que engloba 15 recipientes fragmentados cuya forma no es identificable con seguridad.

\subsection{El utillaje lítico}

El registro lítico tallado constituye por su número, variedad y calidad, uno de los elementos más representativos de los ajuares depositados en las sepulturas. Su estudio se ha centrado en la reconstrucción tecnológica de los procesos vinculados a la producción y al uso de estos instrumentos. En las inhumaciones se han recuperado 203 elementos, clasificados [Roig y Coll 2008 (21)] como núcleos (20), soportes laminares (110), lascas (2), puntas (20), elementos geométricos (50) e indeterminados (1).

Todos estos productos están tallados sobre rocas silíceas a excepción de un núcleo de cuarcita y una laminilla de obsidiana, de $31 \mathrm{~mm}$ de longitud, obtenida por presión. La presencia de esta materia prima en el Neolítico del noreste de la Península Ibérica es un hecho extraordinario por la lejanía de sus posibles zonas de aprovisionamiento, si bien existen precedentes como el pequeño núcleo de laminillas de Bòbila Padró (Ripoll y Llongueras 1963), dos láminas fragmentadas de la sepultura MS17 de Bòbila Madurell (Gibaja 2003) y la lámina de la Mina 83 de Gavà (Borrell et al. 2005, Bosch et al. e.p.).

El resto de materias primas minerales empleadas para la producción del instrumental tallado en Can Gambús-1 corresponde mayoritariamente a rocas silíceas. Se tiende a considerar la mayor parte de las rocas silíceas recuperadas en los contextos de sepulcros de fosa del Neolítico medio catalán como sílex melado de origen provenzal. Sin embargo, un examen más detallado de esta muestra nos permite observar la presencia de rocas silíceas procedentes de otros contextos geológicos, a falta de los pertinentes análisis que permitan corroborarlo. Entre éstas, hemos detectado

(21) Véase nota 3. 
la presencia de rocas silíceas que podrían proceder de las secuencias deposicionales del relleno sedimentario bien del sector oriental de la cuenca del Ebro (Eoceno -Priaboniense terminal- y Oligoceno; Anadón et al. 1989), bien de la cuenca de Bages-Sigean (Oligoceno superior y Mioceno -Aquitaniense-; Grégoire et al. 2009), así como de formaciones calizas y yesíferas localizadas en las comarcas del sur de Cataluña (Eoceno -luteciense a priaboniense-; Doce y Alcobé 1997).

Ya hemos manifestado en otras ocasiones (Gibaja 2003, Gibaja y Terradas 2005; Terradas y Gibaja 2001, 2002) nuestra opinión favorable a una procedencia provenzal del denominado sílex melado como hipótesis más plausible en función de los datos disponibles, a falta de su contrastación analítica y de estudios más detallados que precisen su origen en función de una mejor caracterización de la variabilidad de este sílex (Binder 1998; Blet et al. 2000; Briois 2005; Léa 2005).

El estudio de los núcleos y de los soportes generados a partir de su explotación denota un único tipo de transformación de la materia prima, basada en la producción de láminas y laminillas mediante la técnica de la presión.

Los atributos de los núcleos permiten reconocer como soporte original lascas bastante espesas talladas mediante percusión directa con percutor duro. Estos núcleos han sido transformados mediante un único frente de explotación laminar, generando una sección característica de morfología cónica en cuyo vértice se ubica una única cresta, conformada uni o bifacialmente, centrada o lateralizada, que abarca la totalidad del dorso y del fondo del núcleo. Los soportes se obtuvieron desde una única plataforma de explotación creada, normalmente, a partir de una gran extracción obtenida mediante la percusión directa con percutor duro, cuyo contrabulbo es reconocible en algunos de los núcleos.

La combinación en los mismos núcleos de sílex melado de facetas rojizas y apariencia mate, con otras sin tal rubefacción rojiza y con lustre térmico denota que fueron sometidos a un tratamiento térmico después de su configuración, una vez que ya se habían emplazado sus elementos estructurales, pues es habitual que la plataforma de presión y los flancos conserven restos de zonas enrojecidas. En Can Gambús-1 no disponemos de restos líticos atribuibles a la configuración de los núcleos, con lo que creemos que tanto su preparación como su tratamiento térmico fue- ron realizados fuera del lugar, probablemente en otros contextos más próximos a las áreas de aprovisionamiento de esta materia prima (Terradas y Gibaja 2001, 2002). Este hecho difiere de los datos de Bòbila Madurell, donde las lascas representan el 22,5\% del registro lítico de las sepulturas, o del Camí de Can Grau, donde alcanzan el $13,1 \%$ del conjunto (Gibaja 2003).

La obtención de las láminas y las pequeñas operaciones vinculadas al acondicionamiento de la plataforma de presión y al mantenimiento de los flancos del núcleo pudieron realizarse in situ (Terradas y Gibaja 2002), como muestra el remontaje realizado entre un núcleo y una lámina depositados como elementos de ajuar en la misma sepultura (E668) (Lám. VI). Asimismo hemos podido establecer remontajes entre láminas procedentes de una misma tumba (E70, E122, E167, E515 y E497). Todo ello permite proponer una producción específica de esos soportes laminares como elementos de ajuar, sin que haya mediado un uso previo. En ocasiones, los mismos procedimientos técnicos han sido practicados sobre materias primas de origen local, como la cuarcita, sin motivo técnico alguno que lo justifique.

Poca cosa podemos decir hasta el momento de los soportes laminares y de su modificación. Únicamente constatamos que algunos fueron reto-

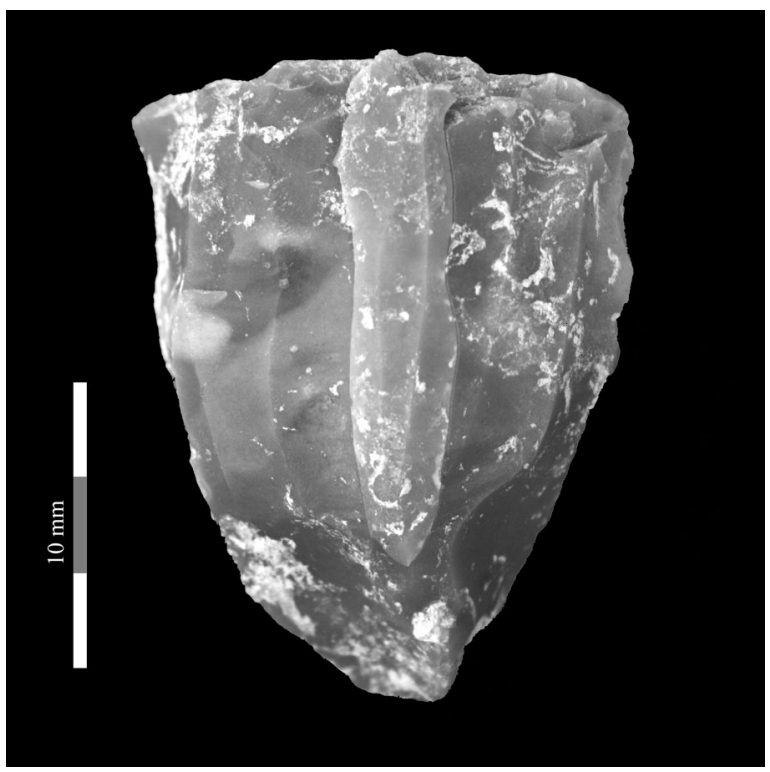

Lám. VI. Núcleo de sílex al que remonta una lámina sin utilizar recuperados en la tumba E668 de Can Gambús-1 (Sabadell, Barcelona) (J.F.Gibaja y X. Terradas). 
cados en sus laterales o transformados en puntas y en elementos geométricos (trapecios y triángulos).

Se ha realizado un estudio traceológico sobre 183 efectivos: $96(52,4 \%)$ han sido utilizados, 73 $(39,9 \%)$ no muestran modificación alguna por el uso y los 14 restantes $(7,7 \%)$ se han catalogado como no analizables. Sobresalen los útiles destinados a la siega de cereales y a servir como proyectiles. Menor porcentaje muestran los instrumentos empleados para procesar materias blandas animales como la carne o en el tratamiento de pieles, y sólo puntualmente hemos documentado alguna pieza usada para trabajar materias óseas. En cambio, faltan los útiles usados sobre materias duras o semiduras como la madera, el asta o la piedra.

Diferenciamos dos tipos de útiles en el procesado de cereales: los empleados para segar y los usados para separar sobre el suelo la espiga de los tallos o cortar los propios tallos (Gibaja 2003). Como en otros muchos contextos neolíticos del noreste peninsular (La Draga, Bòbila Madurell, Camí de Can Grau, Plansallosa, Cova del Frare, ...), la distribución de los micropulidos de uso nos indica que los filos líticos se disponían paralelamente al vástago de la hoz (Gibaja 2000, 2002, 2003).

Muchos de los elementos geométricos fueron usados como elementos de proyectil. En ellos se aprecian pequeñas fracturas como consecuencia de impactos violentos, que sin embargo no debieron inutilizarlos. Hemos podido identificar algunos posibles residuos de enmangue, situados en las aristas centrales o en el lateral sin retocar de menor longitud.

Varias láminas se han empleado especialmente para cortar piel, en algunos casos seca. En otros casos el lustre térmico y el escaso grado de desarrollo de los rastros nos han impedido aproximarnos al estado en el que las pieles se encontraban cuando fueron tratadas. En otras láminas la presencia de melladuras bifaciales de reducido tamaño y la aparición en zonas elevadas de micropulidos muy compactos, similares a los que se originan por el contacto con una materia ósea, nos llevan a la conclusión que se destinaron a tareas de descarnado y despiece, y no al fileteado o corte de carne.

Finalmente respecto a los restos que no han sido usados cabe apuntar que:
- La mayor parte corresponden a soportes laminares enteros o con pequeñas fracturas distales, es decir, en perfecto estado. Algunas de estas láminas son de longitud considerable, ya que superan los $80 \mathrm{~mm}$ de longitud.

- Los geométricos también se encuentran en perfecto estado.

- Algunas láminas enteras o geométricos sin utilizar fueron seleccionados para formar parte del ajuar funerario. El hecho de que remonten varias láminas depositadas en un mismo enterramiento denota que fueron talladas ex profeso con ese fin. Hemos remontado láminas y núcleo/láminas de varias sepulturas, pero hasta el momento ningunas procedentes de distintas sepulturas que nos permitieran establecer vínculos de contemporaneidad.

\section{A MODO DE CONCLUSIÓN}

La información presentada en las páginas precedentes es un claro reflejo de la importancia de la recientemente excavada necrópolis de Can Gambús-1 para el conocimiento de las prácticas funerarias del Neolítico medio del noreste peninsular, así como de la organización social y económica del grupo que fue inhumado.

El magnífico registro arqueológico obtenido, el análisis paleoantropológico y los primeros análisis paleotafonómicos llevados a cabo, nos han ofrecido un conjunto de datos hasta ahora desconocidos en la arqueología catalana de este período. Hoy sabemos mucho más sobre la construcción de las sepulturas y sus características morfológicas, sobre el continuo empleo de materiales perecederos (quizás maderas, vegetales no leñosos y pieles) en la conformación de tales tumbas, así como en la elaboración de estructuras a modo de ataúdes o de sacos a modo de mortajas. La complejidad de estos enterramientos nos han permitido configurar una nueva tipología funeraria, diferente a la establecida hasta ahora por la información que se barajaba. Estos resultados deben acabar de perfilarse cuando sigamos profundizando en los datos recogidos durante la excavación arqueológica y acabemos el análisis paleotafonómico.

Pero no sólo el continente ha aportado novedades, también el contenido. Uno de los aspectos más significativos, ya apreciados durante el proceso de excavación de la necrópolis, es la riqueza 
de los ajuares, tanto en su cantidad como su calidad, que acompañan a ambos sexos. En todo caso, este es un primer trabajo que culminará en un futuro próximo en una monografía.

\section{BIBLIOGRAFÍA}

Anadón, P.; Cabrera, L.; Colldeforns, B. y Sáez, A. 1989: "Los sistemas del Eoceno superior y Oligoceno del sector oriental de la Cueva del Ebro". Acta Geológica Hispánica, 24 (3-4): 205-230.

Binder, D. 1998: "Silex blond et complexité des assemblages lithiques dans le Néolithique liguro-provençal'. En A. d'Anna y D. Binder (eds.): Production et identité culturelle. Actualité de la recherche. Éditions APDCA, Antibes: 111-128.

Blet, M.; Binder, D. y Gratuze, B. 2000: "Essais de caractérisation des silex bédouliens provençaux par analyse chimique élémentaire". Revue d'Archéometrie 24: 149-168.

Borrell, F.; Estrada, A.; Bosch, J. y Orri, E. 2005: "Excavaciones recientes en las minas neolíticas de Gavà -sector sierra de las Ferreres- (Baix Llobregat, Barcelona): nuevos datos para el conocimiento de los rituales funerarios". En P. Arias, R. Ontañón y C. García-Moncó (eds.): III Congreso del Neolítico en la Península Ibérica (Santander, 2003). Instituto Internacional de Investigaciones Prehistóricas de Cantabria, Santander: 635-642.

Bosch, J.; Gibaja, J.F. y Gratuze, B.E. e.p.: "Studio di una lama di ossidiana che procede dalla Sardegna trovata nelle mine neolithiche di Gavà (Barcelona): contesto della scoperta, tipología, analisi funzionale e caratterizazzione geochimica". Vth International Conference. Monte Arci Obsidian in the Mediterranean: advances in the studies of diffusion, production systems and their chronology (Pau, Italia, 2008).

Briois, F. 2005: Les industries de pierre taillée néolithiques en Languedoc occidental: nature et évolution des outillages entre les 6eme et 3eme millénaires av. J.-C. Monographies d'Archéologie Méditerranéenne 20 . Lattes.

Brothwell, D.R. 1987: Desenterrando huesos. Fondo de Cultura Económica. México.

Costa, F.; García, P.; Marcet, R. y Mas, J. 1982: “El Jaciment prehistòric de Can Soldevila (Santa Perpètua de Mogoda)". Fulls d'Arqueològia i Historia de Santa Perpètua de Mogoda. Publicacions del Museu Municipal de Santa Perpètua de Mogoda, Santa Perpètuia de Mogoda: 9-48.

Chimenos, E. 1990: Estudio paleoestomatológico de poblaciones prehistóricas de Catalunya. Libros Pórtico, Zaragoza.
Doce, R. y Alcobé, X. 1997: “Crystallinity index of some cherts from the Ulldemolins complex and the Montblanc formation (Tarragona, Spain)". En A. Ramos y M.A. Bustillo (eds.): Siliceous rocks and culture (VIth International Flint. Symposium). Universidad de Granada, Granada: 111-116.

Duday, H. 1995: “Anthropologie de 'terrain', archéologie de la mort”. En R. Joussaume (ed.): La mort passé, présent, conditionnel (Actes du colloque de La Roche-sur-Yon, juin 1994). Groupe Vendéen d'Etudes Préhistoriques, La Roche-sur-Yon: 33-75.

Esteve, F. 1999: Recerques arqueològiques a la Ribera Baixa de l'Ebre. Prehistòria. Museu del Montsià, Amposta.

Gibaja, J.F. 2000: "La función del instrumental lítico tallado de la Draga (Banyoles, Pla de l'Estany)". En A. Bosch, J. Tarrús y J. Chinchilla (eds.): El poblat lacustre neolitic de la Draga. Excavacions 1990-1998. Centre d'Arqueologia Subaquàtica de Catalunya, Girona: 206-213.

Gibaja, J.F. 2002: "Las hoces neolíticas del noreste de la Península Ibérica". Préhistoire Anthropologie Méditerranéennes 10-11: 83-95.

Gibaja, J.F. 2003: Comunidades neoliticas del noreste de la Península Ibérica. Una aproximación socioeconómica a partir del estudio de la función de los útiles líticos. British Archaeological Reports (international series) S1140, Oxford.

Gibaja, J.F. 2004: "Prácticas funerarias durante el Neolítico en Cataluña". Mainake 26: 9-27.

Gibaja, J.F. y Terradas, X. 2005: "Exploitation du silex blond et organisation technique de la production lithique au Néolithique moyen dans le nord-est de la Péninsule ibérique". En J. Jaubert y M. Barbaza (eds.): Territoires, déplacements, mobilité, échanges durant la Préhistoire. Éditions du Comité des Travaux Historiques et Scientifiques, Paris: 525-536.

Gibaja, J.F. y Terradas, X. 2008: "La industria lítica de la necrópolis de Can Gambús (Sabadell, Barcelona). Primeros resultados del análisis tecno-morfológico y funcional". En M. Hernández, J.A. Soler y J.A. Lopez (eds.): IV Congreso del Neolítico en la Península Ibérica (Alicante, 2006). Alicante: 178-183.

Grégoire, S.; Bazile, F. y Boccaccio, G. 2009: "Ressources lithiques en Languedoc-Roussillon et territoires d'exploitations au Paléolithique supérieur". En F. Djindjian, J. Kozlowski y N. Bicho (eds.) Le concept de territoires dans le Paléolithique supérieur européen. British Archaeological Reports (international series) S1938, Oxford: 183-199.

Guitart, I. 1986: "La necropolis neolitica del Pla del Riu de les Marcetes (Manresa, Bages)". Tribuna de Arqueologia 1986-1987: 41-47.

Léa, V. 2005. "Raw, pre-heated or ready to use: discovering specialist supply systems for flint industries 
in mid-Neolithic (Chassey culture) communities in southern France". Antiquity 79: 51-65.

Leroi-Gourhan A. 1975: Séminaire sur les structures d'habitat: sépulture. Collège de France, Paris.

Llongueras, M.; Marcet, R. y Petit, M.A. 1981: "La cultura catalana de los Sepulcros de Fosa y su relación con el Chasseense". En J.P. Demoule y J. Guilaine (dirs.): Le Néolithique de la France. Hommage à G. Bailloud. Picard, Paris: 251-258.

Maluquer de Motes, J. 1950: "La cultura neolítica del Vallés en el marco de la Prehistoria del Occidente Mediterráneo". Arraona 1-2: 61-75.

Martí, M.; Pou, R. y Carlús, X. 1997: Excavacions a la Ronda Sud de Granollers, 1994. La necròpolis del neolític mitjà i les restes romanes del Cami de Can Grau (la Roca del Vallès, Vallès Oriental). Els jaciments de Cal Jardiner (Granollers, Vallès Oriental). Excavacions Arqueologiques a Catalunya 14. Departament de Cultura de la Generalitat de Catalunya, Barcelona.

Martín A. 2009: "Les sociétés du Néolithique moyen en Catalogne et leur gestion du funéraire". En J. Guilaine (dir.): Sépultures et sociétés: Du Néolithique à l'Histoire. Editions Errance, Paris: 45-67.

Mestres, J. 1988/1989: "Les sepultures neolítiques de l'Hort d'en Grimau (Castellví de la Marca, Alt Penedès)". Olerdulae, Revista del Museu de Vilafranca 1-4: 97-129.

Molist, M.; Cruells, W. y Castells, J. 1987: “L'àrea megalítica de Tavertet (Osona)". Cota Zero 3: 55-68.

Molist, M.; Vicente, O. y Farré, R. 2008: “El jaciment de la Caserna de Sant Pau del Camp: aproximació a la caracterització d'un assentament del Neolític antic". Quaris 4: 15-24.

Muñoz, A.M. 1965: La cultura neolítica catalana de los Sepulcros de Fosa. Publicaciones eventuales 9.
Instituto de Arqueología y Prehistoria de la Universidad de Barcelona, Barcelona, 1965.

Olivier, G. 1960: Practique Anthropologique. Vigot Fréres Eds. Paris.

Ripoll, E. y Llongueras, M. 1963: "La cultura neolítica de los Sepulcros de Fosa en Cataluña". Ampurias XXV: $1-90$.

Riuró, F. y Fusté, M. 1980: Les estacions prehistoriques del Puig d'En Roca. Vol. II: Les necrópolis del Neolític final de Sant Julià de Ramis i del Puig d'En Roca (Girona). Associació Arqueológica de Girona, Girona.

Roig, J. y Coll, J.M. 2007: "El paratge arqueològic de Can Gambús 1 (Sabadell, Vallès Occidental)". Tribuna d'Arqueologia 2006-2007: 85-109.

Roig, J. y Coll, J.M. e.p.: "La necròpolis neolítica de sepulcres de fossa de Can Gambús 1 (Sabadell, Vallès Occidental)". Cypsela 18.

Serra-Ràfols, J. de C. 1947: "La exploración de la necrópolis neolítica de la Bòbila Madurell en Sant Quirze de Galliners". Museo de la Ciudad de Sabadell III: 57-75.

Tarrús, J. 1981: "El Neolític Mitjà a les comarques gironines". El Neolític a Catalunya (Taula Rodona de Montserrat, 1980). Publicacions de l'Abadia de Montserrat, Montserrat (Barcelona): 87-102.

Terradas, X. y Gibaja, J.F. 2001: “El tratamiento térmico en la producción lítica: el ejemplo del Neolítico medio catalán”. Cypsela 13: 29-56.

Terradas, X. y Gibaja, J.F. 2002: "La gestión social del sílex 'melado' durante el Neolítico medio en el noreste de la Península Ibérica". Trabajos de Prehistoria 59 (1): 29-48.

Villalba, J.; Bañolas, L.; Arenas, J. y Alonso, M. 1986: Les mines neolítiques de Can Tintorer, Gavà, Excavacions 1978-1980. Excavacions arqueològiques a Catalunya 6. Departament de Cultura de la Generalitat de Catalunya, Barcelona. 